\title{
Juicios expresados por niñas y niños de 9 a 11 años de edad sobre comportamientos y actitudes que conducen a la aceptación o al rechazo social en un grupo escolar
}

\section{Judgments expressed by children between 9 to 11 years old, about behaviors and attitudes that lead to acceptance or social rejection in a school group}

\author{
Jorge Mario Jaramillo Pérez* \\ Tatiana Cárdenas Maldonado \\ Camila Forero Andrade \\ Dinian Ramírez Díaz ${ }^{* *}$ \\ Universidad Santo Tomás, \\ Bogotá, Colombia
}

Recibido: diciembre 14 de 2006

Revisado: enero 22 de 2007

Aceptado: enero 30 de 2007

\section{Resumen}

Este estudio buscó identificar comportamientos y actitudes que asocian niños y niñas, entre los 9 y 11 años de edad, con la aceptación y el rechazo social en un grupo escolar. Se pidió a los niños y niñas hacer estimaciones sobre la importancia que distintas cualidades y defectos tienen como factores que contribuyen a que un niño sea aceptado, o por el contrario, sufra el rechazo de sus compañeros de colegio. Para la recolección de los datos, se utilizaron tres instrumentos: un test sociométrico, un cuestionario sobre cualidades que contribuyen a que el niño goce de aceptación social y un cuestionario sobre defectos que conducen al rechazo de los compañeros. Estos instrumentos se aplicaron colectivamente en el aula de clase con la instrucción de responder independientemente sin comentar sus respuestas con sus compañeros. Los datos obtenidos fueron procesados estadísticamente a través de análisis de correlación y de varianza. La mayoría de los niños coincidió en sus juicios sobre el grado de importancia de algunas cualidades y algunos defectos. Al comparar niños y niñas, se observaron diferencias significativas en sus apreciaciones sobre algunas cualidades. El grado de integración social ostentado por los niños en su grupo

Correspondencia: Jorge Mario Jaramillo, docente de la Facultad de Psicología de la Universidad Santo Tomás. Correo electrónico: jorgejaramillo@usta.edu.co. Dirección postal: Cra. 9 No. 51 -11, Bogotá, Colombia.

.* Estudiantes próximas a graduarse en la Facultad de Psicología de la Universidad Santo Tomás. 
escolar no pareció incidir en forma significativa sobre los juicios que expresaron. Los resultados sugieren algunos perfiles prototípicos de niños aceptados y rechazados en los grupos escolares.

Palabras clave: aceptación, rechazo, cualidades, defectos, pares, juicios.

\begin{abstract}
The aim of this study was to identify behaviors and attitudes that children, between the 9 and 11 years of age, associate with the acceptance and the social rejection within a school group. Children were asked to make estimations about the importance that different qualities and defects have as factors that contribute to that a boy could be accepted, or on the contrary, feel the rejection of its schoolmates. To collect the information, tree measuring instruments were used: a socio-metric test, a questionnaire on qualities that contribute a child to enjoy to be accepted and a questionnaire on defects that lead to the rejection of the partnerships. These instruments were applied collectively in the classroom, but it was asked each boy to respond independently without commenting its answers with its classmates. The collected data were process statistically through variance and correlation analysis. Most of the children's answer coincided on the degree of importance of some qualities and some defects. The degree of social integration shown social integration shown by the children within its scholar group did not seem to affect significant form the judgments that expressed. The results suggest some prototypes profiles of accepted and rejected children to the interior of the scholar groups.
\end{abstract}

Key words: acceptance, reject, qualities, defects, pairs, judgments.

\section{Introducción}

El presente estudio hace parte de una investigación docente que se realiza en la Facultad de Psicología de la Universidad Santo Tomás con el objetivo de identificar factores individuales, familiares y escolares asociados a la aceptación y al rechazo social en grupos escolares de niños entre los 9 y 11 años de edad.

Esta investigación se inició en febrero de 2005 como resultado de la preocupación creciente observada en las instituciones educativas por mejorar los procesos de socialización para favorecer el desarrollo de inteligencia emocional en los niños y prevenir fenómenos de violencia, discriminación y aislamiento social que se presentan frecuentemente en los grupos escolares (Jaramillo, 2004).
En la comunidad científica existe cada vez mayor consenso sobre la importancia crucial que tienen, para la socialización y el desarrollo de la personalidad, las relaciones que los niños establecen con sus pares durante los años de su aprendizaje escolar. En efecto, podría afirmarse que en ese período de la vida se sientan las bases de la autoestima y el autoconcepto personal, así como de las actitudes y comportamientos que cada sujeto humano pondrá de manifiesto posteriormente al interactuar con las personas que lo rodean (Bagwell, Newcomb y Bukowski, 1998). Los rápidos cambios en la ciencia y la tecnología, en la cultura y la organización social que experimenta el mundo actual han traído como consecuencia un ingreso cada vez más temprano de los niños al sistema escolar, con lo que a la influencia de las experiencias familiares se suma cada vez con mayor fuerza la influencia de las experiencias que 
se acumulan diariamente en la escuela, gran parte de las cuales involucran la interacción con otros niños de edad similar (Rice, 1997).

El presente estudio pretende aportar información sobre la forma en que los niños y niñas de 9 a 11 años de edad perciben las pautas que rigen las relaciones sociales en un grupo escolar.

\section{Variables relacionadas con la aceptación y el rechazo social en los grupos escolares}

La asistencia a la escuela brinda a los niños la oportunidad de ampliar sus contactos sociales más allá de la familia. La calidad de las relaciones sociales que se establecen en estos primeros años parece ejercer una fuerte influencia sobre el grado de satisfacción y éxito social que experimente posteriormente la persona durante su adolescencia o en la edad adulta (Díaz Aguado, 1996).

Piaget (1965) fue uno de los primeros en resaltar la importancia que tienen las relaciones entre iguales para el desarrollo de la autonomía. Desde su punto de vista, en la relación que existe entre el adulto y el niño prima la desigualdad. El adulto detenta una posición de poder y de depositario del saber que difícilmente puede intercambiar con el niño. Esta desigualdad favorece las relaciones heterónomas. Entre los niños de la misma edad predomina, por el contrario, la igualdad y ello favorece el entendimiento gradual de la reciprocidad y de la importancia de cooperar, como un medio a través del cual se pueden establecer vínculos, al tiempo que se logra el reconocimiento y la aceptación de los otros.

En principio, puede concebirse el grupo de pares como un campo de entrenamiento privilegiado en el que los niños se ejercitan día tras día en actitudes y comportamientos sociales que aplicarán luego regularmente en otros contextos sociales.

Tener amigos o estar vinculado afectivamente con otros proporciona un espacio para compartir ex- periencias, expresar sentimientos y resolver conflictos, a la vez que se recibe retroalimentación sobre como uno es percibido y valorado por los demás. No tener amigos, por el contrario, conduce al aislamiento o a contactos sociales muy restringidos, por lo que se dispone de pocas oportunidades para obtener reconocimiento y desarrollar habilidades de interacción social (Díaz Aguado, 1996). Nos encontramos aquí frente a una especie de círculo vicioso: la falta de amistades y de contactos sociales trae consigo escasas oportunidades de aprendizaje en este campo, de esto se deriva un déficit en habilidades sociales que, a su vez, obstaculiza el establecimiento de contactos satisfactorios con otros...

Surge la pregunta: ¿qué es lo que hace la diferencia entre los niños que gozan de gran aceptación social y los niños que, por el contrario, son rechazados por sus compañeros? Según Rodríguez y González (2002), una característica importante de los grupos de iguales es poseer una cultura diferenciada que incluye valores, lenguaje y pautas de comportamiento. Cabría suponer que el grado en que cada niño logre interpretar adecuadamente esta cultura y responder a sus demandas influye sobre su éxito o fracaso en el esfuerzo por hacerse a una buena posición en el grupo.

Pero, ¿en qué consiste concretamente esta cultura?, ¿cómo varía ella de acuerdo con la edad o el contexto social y escolar en que se desenvuelven los niños? Selman (1980) ha sugerido que existen diferencias en la forma como los niños de diferentes edades hacen amistades. Desde su punto de vista, el concepto de amistad evoluciona a través de una serie de etapas que están íntimamente relacionadas con el desarrollo cognoscitivo. Con el paso de una etapa a la siguiente, cambian las necesidades e intereses $\mathrm{y}$, como consecuencia, cambian también las experiencias que los niños comparten. Entre los niños preescolares, por ejemplo, el amigo es el compañero de juego, sin importar mucho la calidad de la relación afectiva que se establezca con la persona. En esta etapa, el egocentrismo pondría límites al intercambio recíproco de necesidades y afectos. En los niños de la escuela elemental, se observa en cambio una 
preocupación por las opiniones y juicios que proceden del grupo de pares, se inicia una dependencia afectiva; ya no basta sólo con gozar de compañía, también es importante la validación o el reconocimiento que se obtiene de los otros (Rodríguez y González, 2002).

Desde esta perspectiva, entonces, la clave para que un niño logre iniciar y mantener amistades sería que pueda establecer sintonía con los criterios que predominan en un momento dado en el grupo de iguales y que definen lo que hace a un niño digno $o$ no de recibir la amistad de sus compañeros.

¿Cuáles son estos criterios?, ¿cuáles de ellos tienen mayor peso durante el período de la escuela elemental? Varios investigadores han dirigido su atención al estudio de pautas conductuales que parecen estar relacionadas con la aceptación o el rechazo social dentro de un grupo escolar.

Crick y Dodge (1994) y Dozier (1991) afirman que los niños que son aceptados se diferencian de los niños que son rechazados socialmente por ser mucho más sensibles a las iniciativas sociales de los otros niños, muestran mayor receptividad, brindan más aceptación y buscan activamente el contacto con sus compañeros. Los niños aceptados suelen caracterizarse también por su habilidad para acercarse a sus compañeros de manera positiva, así como expresar deseos y preferencias argumentando sus acciones y posiciones frente a sus compañeros. Por otro lado, participan y negocian activamente en las discusiones importantes que se presentan en las actividades que comparten con sus iguales (Díaz Aguado, 1996; Wentzel y Asher, 1995).

Los niños que sufren rechazo social, por el contrario, llaman mucho más la atención sobre sí mismos, colaboran menos, muestran menos interés por los otros niños y expresan más frecuentemente rechazo en forma de agresiones físicas o verbales, disputas, negación de solicitudes y no seguimiento de sugerencias (Díaz Aguado, 1996; Denham y Holt, 1993). Además, se comunican menos con otros niños (Rubin, 1993, citado en Ladd, 1999); y cuando lo hacen, son más propensos a hacer comentarios irrelevantes, a expresar desacuerdos sin explicar razones ni ofrecer alternativas constructivas y a comunicarse imperso-nalmente (Black y Hazen, 1990).

La investigación sugiere que existen dos perfiles claramente discernibles de niños que con frecuencia se ven expuestos al rechazo social (Ladd, 1999). Aquellos que por medio de su conducta agresiva y de constante confrontación tratan de forzar a los otros niños a aceptarlos y aquellos que no son aceptados debido a su conducta tímida y ansiosa. Los primeros irrumpen constantemente en el espacio privado de los otros, agrediendo, impidiendo sus juegos y conversaciones o presionándolos a volcar la atención sobre ellos, por lo que se ganan su animadversión o agresión (Ladd y Burgess, 1999). Los segundos temen expresar sus sentimientos y hacer valer sus derechos, por lo que llegan pronto a una situación de desventaja con respecto a sus compañeros que difícilmente logran superar (Parker y Seal, 1996). Lo anterior podría resumirse con la interpretación de Monjas (1996), quien considera que son los déficits o excesos conductuales los principales obstáculos para poder establecer una relación positiva con los pares.

Pero, ¿qué respuesta darían los propios niños si se les pide que hagan una estimación sobre el tipo de comportamientos que resultan favorables o desfavorables para desenvolverse exitosamente en un grupo escolar? Es evidente que cada niño, con base en sus experiencias de interacción social, va desarrollando conocimiento acerca de las normas y principios que rigen las relaciones sociales entre pares, lo cual le sirve como una guía para regular su propio comportamiento. La interacción en el grupo de iguales es muy variada: allí se presentan situaciones de colaboración, pero también de conflicto y agresión; todas ellas son una fuente importante y continua de estimulación, aprendizaje y descubrimiento.

En este activo proceso de construcción de conocimiento no sólo están involucrados los niños individuales, sino los grupos humanos como totalidades (Bruner y Haste, 1990). Por eso, es de esperar que haya amplios consensos en la percepción 
que manifiestan los niños de un mismo grupo escolar sobre ciertos asuntos relacionados con sus interacciones sociales.

Por otro lado, es probable que haya diferencias notables entre los grupos de niños y niñas en la forma como perciben su vida social, ya que en cada contexto cultural existen roles que por tradición son asignados preferentemente a hombres o mujeres y esto se reflejaría en la particular configuración de las relaciones sociales que puede aparecer en grupos exclusivamente masculinos 0 femeninos o en grupos mixtos.

Se ha podido constatar, por ejemplo, que los grupos de niñas no sólo tienden a ser más pequeños que los de los niños, sino que parecen funcionar bastante diferente. Las niñas le dan más importancia a la proximidad física y a la conversación íntima; los niños, a los intereses y juegos compartidos (Arenas, 1996). En los grupos de niñas, son frecuentes las conversaciones sobre temas "románticos", pero se castigan con severidad expresiones de la sexualidad que puedan dejar la impresión de "chica fácil" (Delarmont,1990; citada por Arenas, 1996). En los grupos de varones, son más comunes los intercambios agresivos. Algunos de ellos, como darse puntapiés o coscorrones, pueden ser indicadores de gran confianza y simpatía mutuas (Chitiva, 1997); otros, por el contrario, pueden acarrear un rechazo duradero del grupo de iguales. Coie y cols. (1991) ofrecen un análisis interesante al respecto; a partir de observaciones de niños varones en situaciones de juego, concluyeron que la agresión instrumental lleva a reacciones de rechazo en el grupo que pueden prolongarse en el tiempo, mientras que la agresión motivada por un estado de ira tiende a producir sólo efectos pasajeros. Juegos bruscos no traen en cambio ninguna consecuencia, ya que no se atribuye a estos comportamientos ninguna intención agresiva.

La edad y el nivel de desarrollo cognoscitivo de los niños afectan también muy probablemente la forma como los niños perciben sus relaciones sociales y los comportamientos y actitudes a los que atribuyen mayor valor. Por ejemplo, según la teoría sobre el desarrollo moral de Kohlberg (1999), los niños entre los 9 y 11 años se encontrarían ingresando al estadio convencional, un momento del desarrollo en el que reconocen la importancia de las normas morales y entienden su sentido, lo que concuerda con el desarrollo de la capacidad para ponerse en el lugar del otro, generando y manteniendo relaciones mutuas en las que serían importantes la confianza, la lealtad, el respeto y la gratitud.

Tomando como base los interrogantes anteriores, este estudio trató de reunir información sobre el grado de importancia que niños y niñas de 9 a 11 años de edad atribuyen a distintos comportamientos y actitudes, como medios a través de los cuales se puede lograr aceptación dentro de un grupo escolar o, por el contrario, rechazo.

Para cumplir con este propósito, se plantearon los siguientes objetivos:

- Identificar qué comportamientos y actitudes consideran determinantes los niños y las niñas para lograr la aceptación social en un grupo escolar.

- Identificar qué comportamientos y actitudes consideran determinantes los niños y las niñas para generar rechazo social en un grupo escolar.

- Observar si existen o no diferencias entre niños y niñas en los comportamientos y actitudes que perciben como determinantes de aceptación o rechazo social en un grupo escolar.

- Observar si la posición social de un niño o una niña dentro de un grupo escolar se relaciona con cambios en su percepción sobre comportamientos y actitudes asociados a la aceptación o el rechazo social.

De acuerdo con los anteriores, objetivos se formularon las siguientes hipótesis:

H1: Existen coincidencias significativas en las percepciones que exteriorizan los niños sobre comportamientos y actitudes que conducen a la aceptación o al rechazo social dentro de 
un grupo escolar.

H2: Existen diferencias significativas entre niños y niñas en las percepciones que expresan sobre comportamientos y actitudes que generan aceptación o rechazo social en un grupo escolar.

H3: Las percepciones que manifiestan los niños sobre comportamientos y actitudes asociados a la aceptación o al rechazo escolar varían significativamente dependiendo del grado de inclusión (o exclusión) social que se esté experimentando dentro del grupo escolar.

H4: Existen cualidades y defectos que se relacionan entre sí formando grupos de características o "perfiles" de niños que pueden iden- tificarse en un grupo escolar.

\section{Método}

\section{Población}

Niños y niñas mayores de 9 y menores de 12 años que asisten a colegios privados en Bogotá y sus alrededores.

\section{Muestra}

122 niñas y 82 niños pertenecientes a los siguientes colegios:

\begin{tabular}{lccc}
\hline \multicolumn{4}{c}{ Tabla 1. Distribución de la muestra en los colegios del estudio } \\
\hline Colegio & Niñas & Niños & Grado \\
Colegio Santa María & 28 & & Tercero \\
Colegio San Juan de Ávila & 16 & 10 & Cuarto \\
Colegio Andino & 23 & 30 & Cuarto \\
Colegio San Juan de Ávila Campestre & 14 & 27 & Cuarto y quinto \\
Colegio Rosario & 27 & & Cuarto \\
Colegio Hipatia & 16 & 14 & Cuarto \\
\hline
\end{tabular}

\section{Procedimiento}

En cada grupo escolar se aplicaron colectivamente tres instrumentos: un test sociométrico, un cuestionario sobre cualidades personales que son importantes para que el niño sea aceptado por sus compañeros de colegio y un cuestionario sobre defectos que contribuyen a que un niño no sea aceptado por sus compañeros. En el encabezamiento de los dos cuestionarios se decidió utilizar los sustantivos "cualidad" y "defecto", por ser palabras utilizadas comúnmente al referirse a comportamientos elogiables o criticables que manifiesta frecuentemente una persona. Los instrumentos fueron elaborados en el contexto de una investigación más amplia mencionada en la introducción de este artículo (véase Jaramillo, Díaz, Niño, Tavera y Velandia, 2006).

\section{Instrumentos}

A continuación se ofrece una breve explicación sobre cada uno de los instrumentos: 


\section{Test sociométrico ${ }^{2}$}

Tiempo de aplicación: 15-20 minutos.

Objetivo: identificar en cada grupo niños con distintos niveles de integración social .

Forma de aplicación: el test sociométrico se aplicó colectivamente en los distintos grupos escolares, pero cuidando que cada niño lo diligenciara en forma individual. El maestro se mantuvo al margen de cualquier intervención durante la aplicación del instrumento. Para calcular el nivel de integración social de cada niño, se sumaron independientemente los puntajes que obtuvo en las categorías de vinculación, aceptación y cooperación social (preguntas 1, 2 y 4) y los que obtuvo en las categorías de rechazo y aislamiento social (preguntas 3 y 5). Luego, al resultado de la primera suma se le restó el resultado de la segunda. El puntaje resultante constituyó el índice de integración social de cada niño dentro de su grupo escolar.

\section{Cuestionario sobre cualidades}

personales importantes para que un niño goce de buena aceptación social entre sus compañeros de colegio

El tiempo de aplicación de este cuestionario fue de aproximadamente 20 a 25 minutos. En él se hace una lista de supuestas "cualidades" que un niño puede mostrar dentro de su grupo escolar. Los niños deben hacer estimaciones sobre la importancia que tiene cada cualidad descrita para que un niño goce de la aceptación de sus compañeros.

Las opciones de respuesta frente a cada ítem son las siguientes:

$1=$ Nada importante

$2=$ Poco importante

$3=$ Más o menos importante

4= Importante

\section{$5=\quad$ Muy importante}

Se dejó una casilla con el texto: ¿Otra? para que los niños pudieran anotar alguna otra cualidad que en su concepto se debiera tenerse en cuenta y hacer la estimación correspondiente.

Para definir la importancia atribuida a las distintas cualidades, se calculó el promedio de todas las estimaciones hechas por los niños con respecto a cada cualidad.

\section{Cuestionario sobre defectos que contribuyen a que un niño no sea aceptado por sus compañeros de colegio}

Con este cuestionario se procedió de la misma manera que con el anterior.

\section{Resultados}

Los resultados obtenidos con la aplicación del test sociométrico y los cuestionarios sobre cualidades y defectos se procesaron estadísticamente haciendo uso del programa SPSS, versión 0.5.

Las pruebas estadísticas aplicadas para el análisis de los datos fueron la prueba $f$, la prueba $t$, los coeficientes de correlación de Pearson y Spearman y el análisis factorial.

Para la descripción de los resultados se tomaron como guía las preguntas formuladas antes de plantear las hipótesis:

- ¿Qué tanto coinciden los niños en sus juicios acerca del grado de importancia que tienen distintas cualidades para el logro de una buena aceptación social?

Los(as) niños(as) mostraron coincidencias significativas en sus estimaciones sobre un grupo consi- 
derablemente amplio de cualidades. La mayoría de ellos consideró muy importantes las siguientes cualidades (véanse Gráficos 1 a 7 ):

- $\quad$ Ser respetuoso $(71 \%)$.

- $\quad$ Ser fiel con los amigos (67.6\%).

- $\quad$ Ser solidario, ayudar a los demás $(65 \%)$.

- $\quad$ Ser seguro de sí mismo (64.7\%).

- Ser sociable, relacionarse con todos $(60.8 \%)$.

- $\quad$ Ser generoso, saber compartir sus cosas $(58.8 \%)$.

- $\quad$ Ser sincero, infundir mucha confianza (56.4\%).

\section{Gráfico 1. Ser respetuoso}

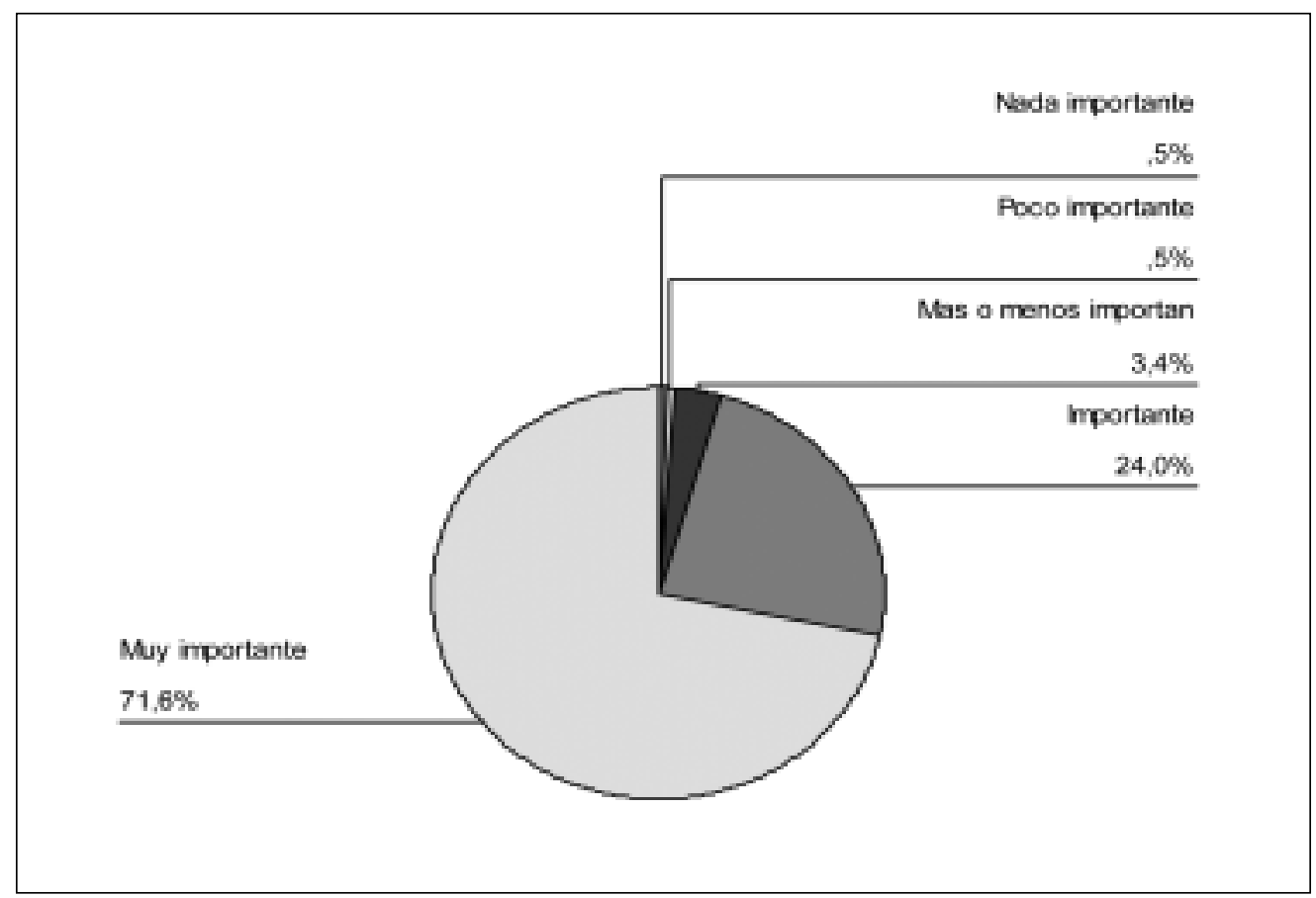


Gráfico 2. Ser fiel con los amigos

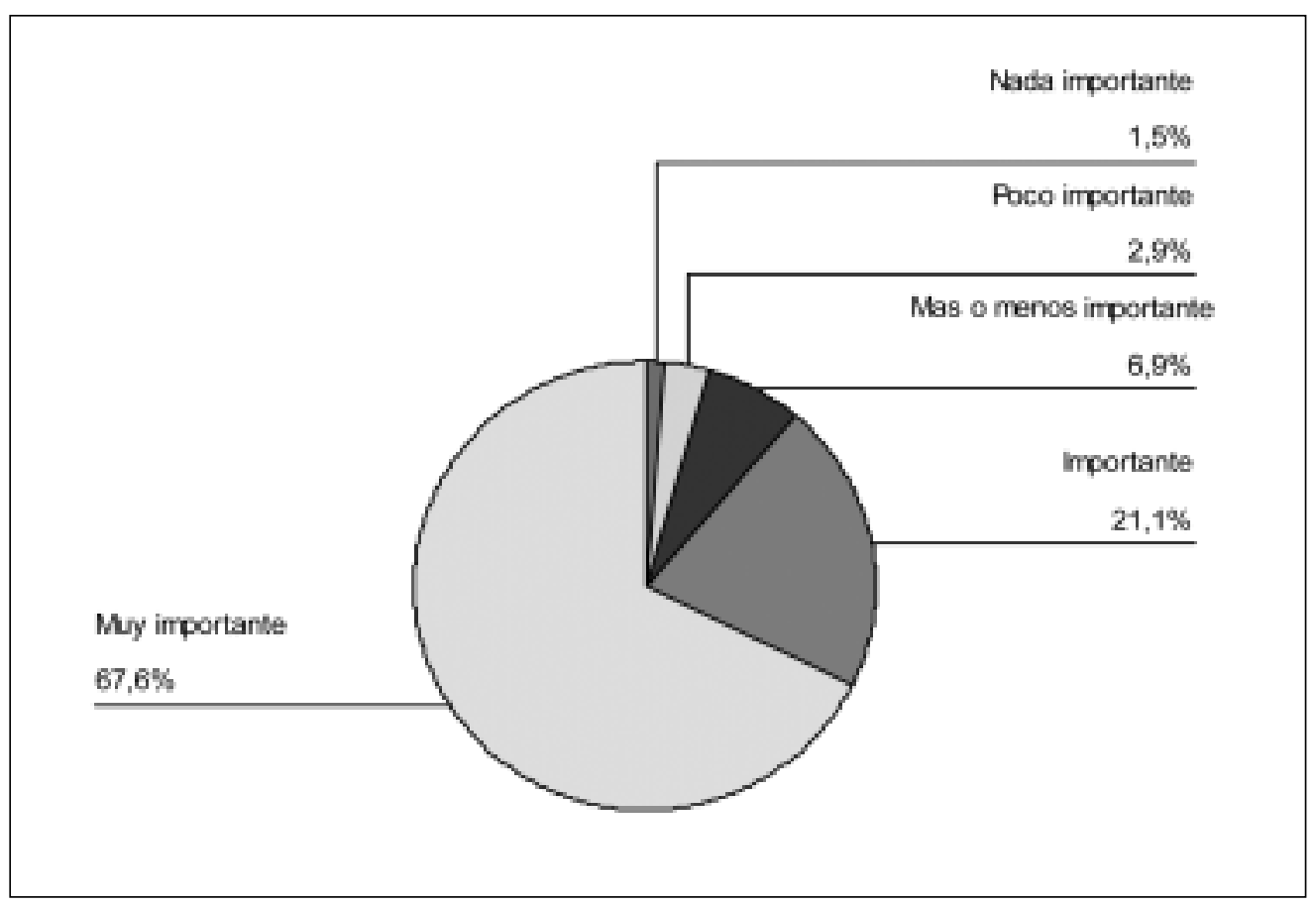

Gráfico 3. Ser solidario, ayudar a los demás

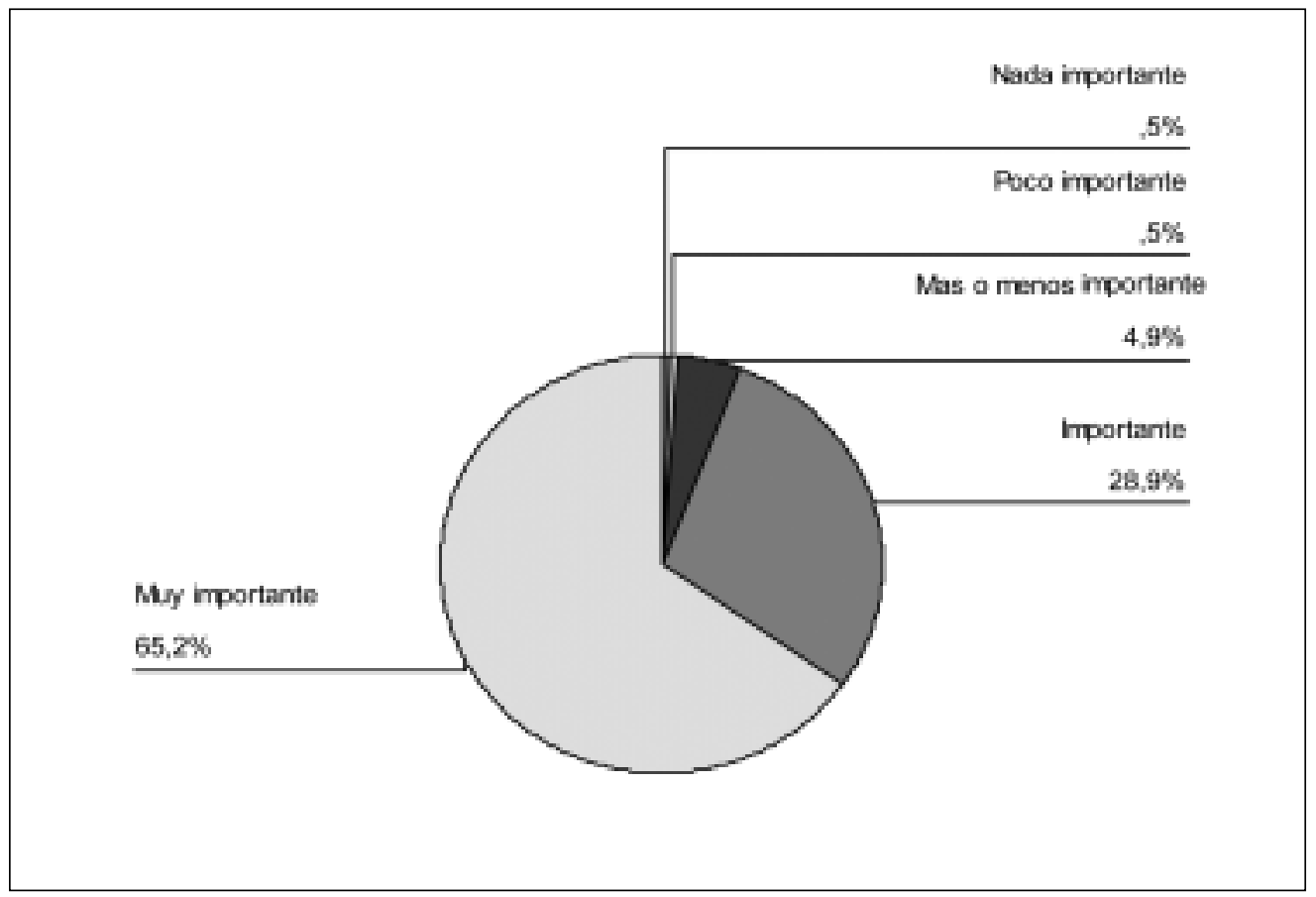


Gráfico 4. Ser seguro de sí mismo

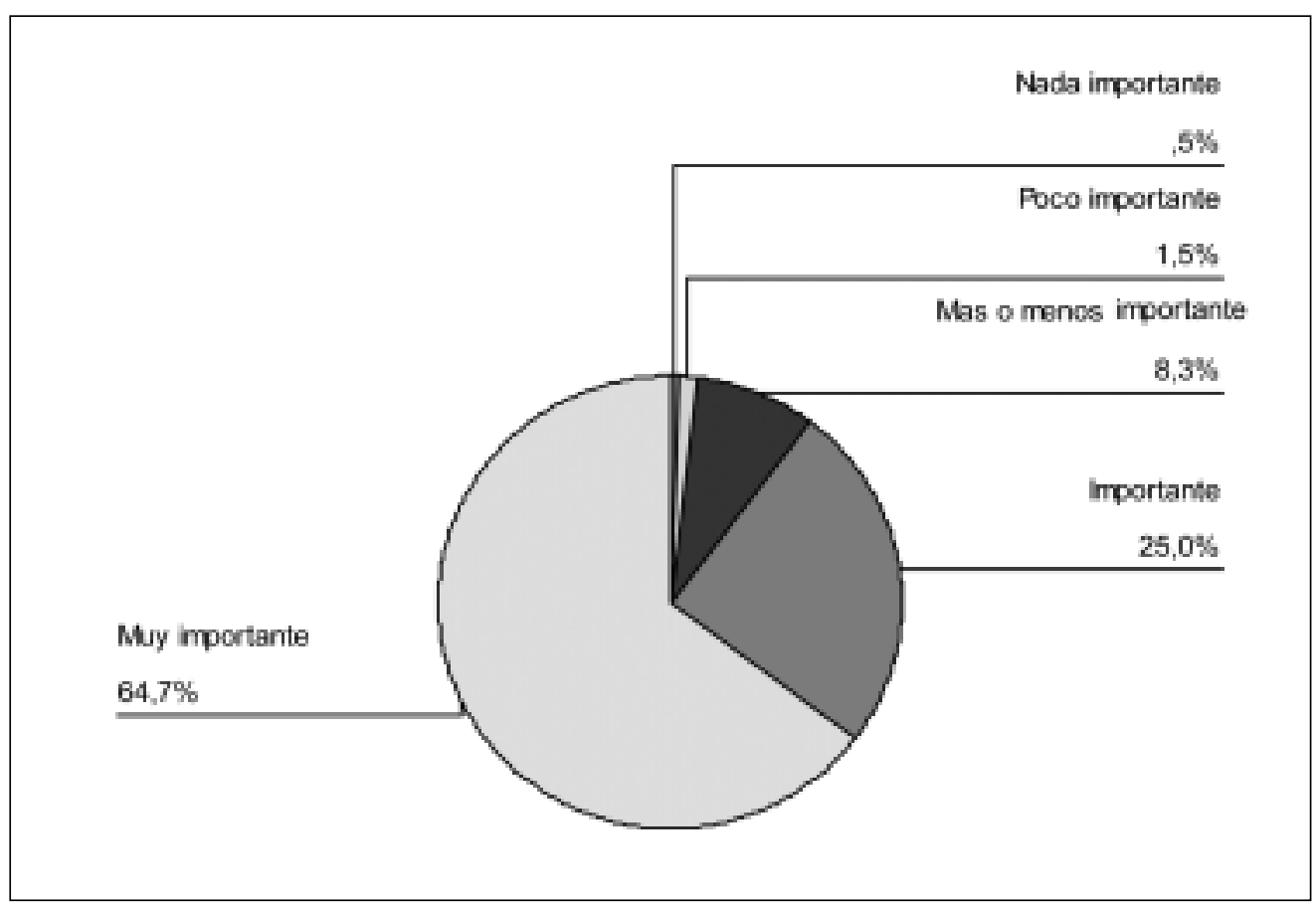

Gráfico 5. Ser sociable, relacionarse con todos

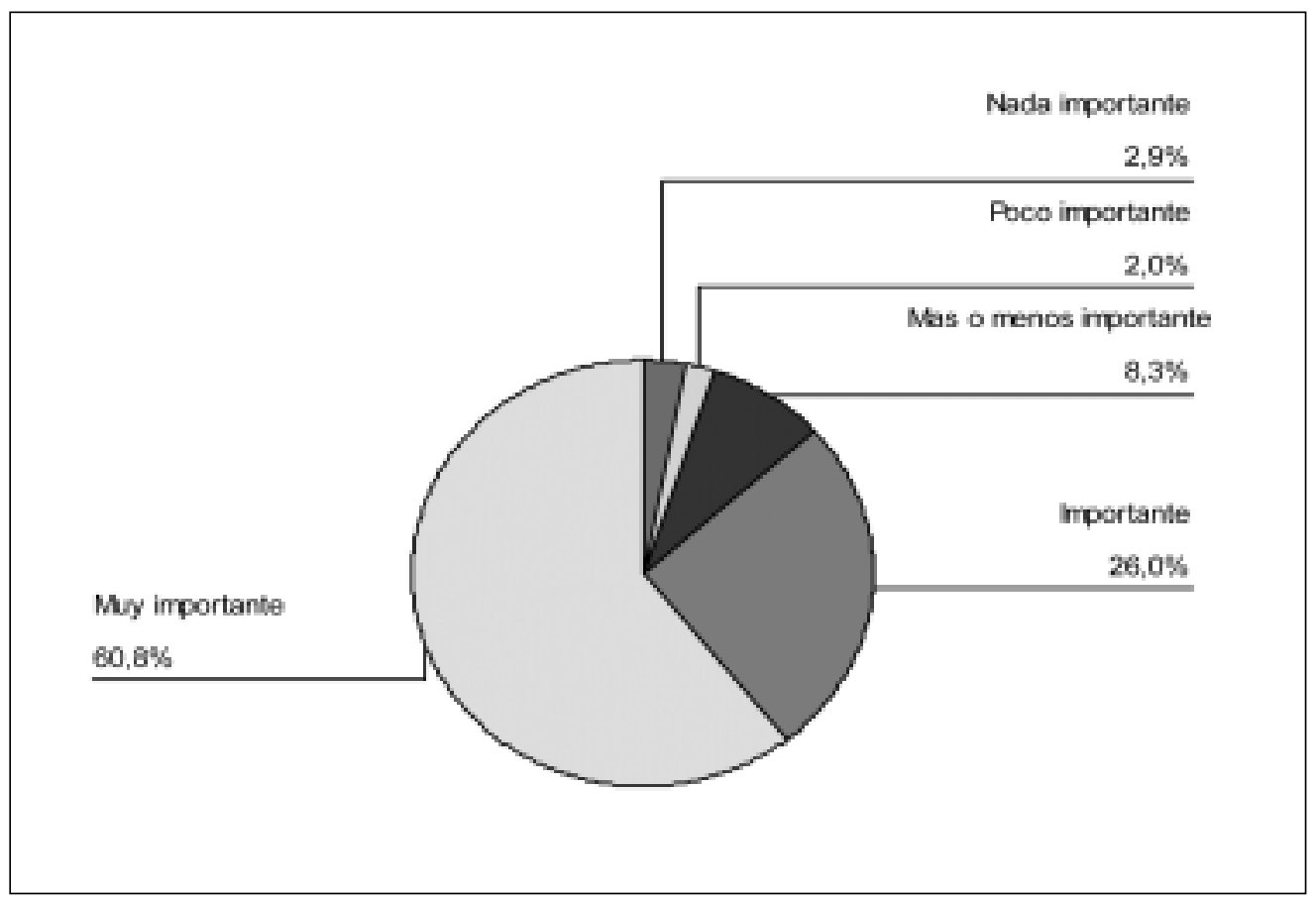


Gráfico 6. Ser generoso, saber compartir sus cosas

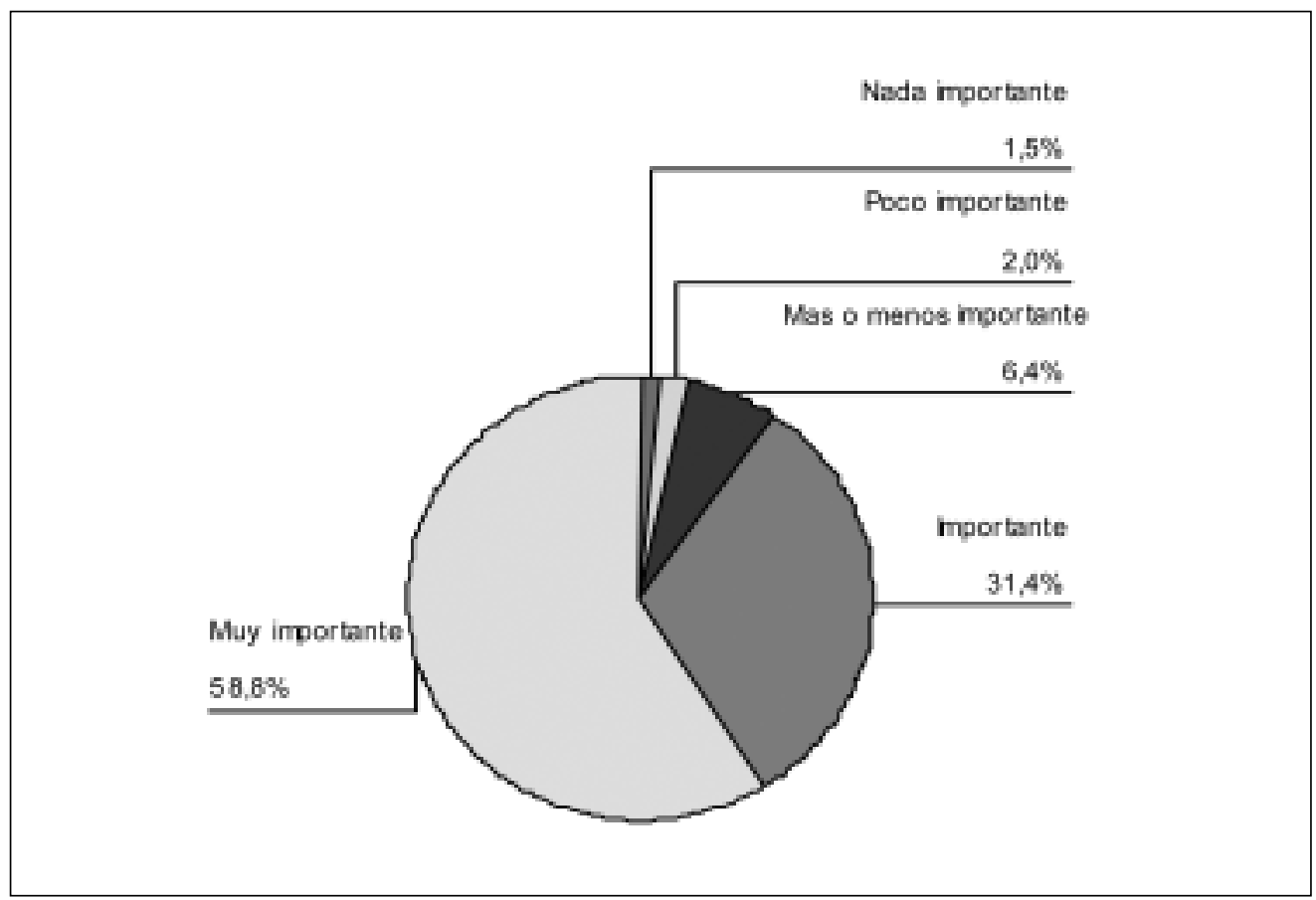

Gráfico 7. Ser sincero, infundir mucha confianza

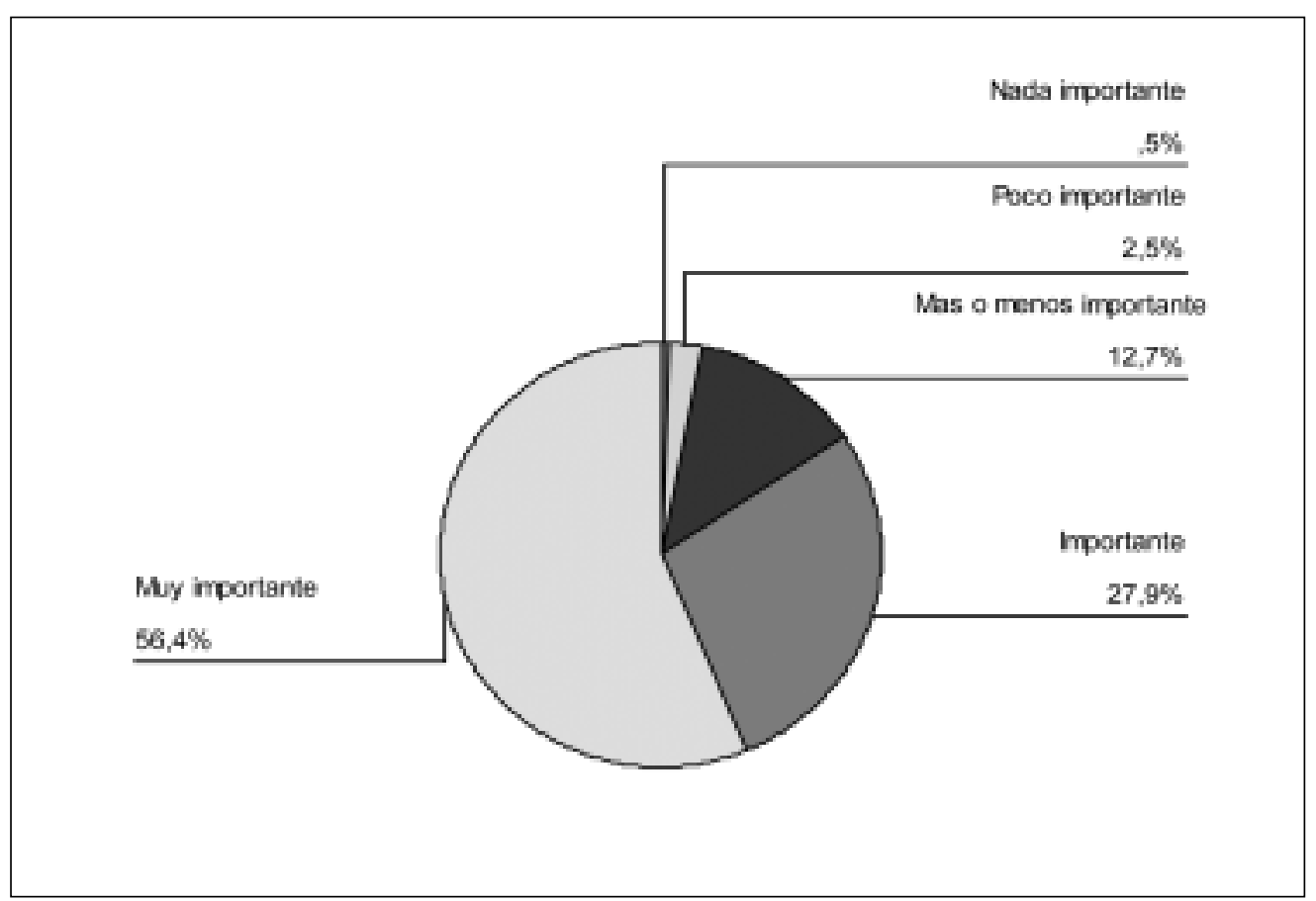


La mayoría de los niños coincidió en juzgar como nada importante la supuesta cualidad de "ser travieso", con un $65.2 \%$ (gráfico 8 ).

Gráfico 8. Ser travieso, molestar mucho en clase

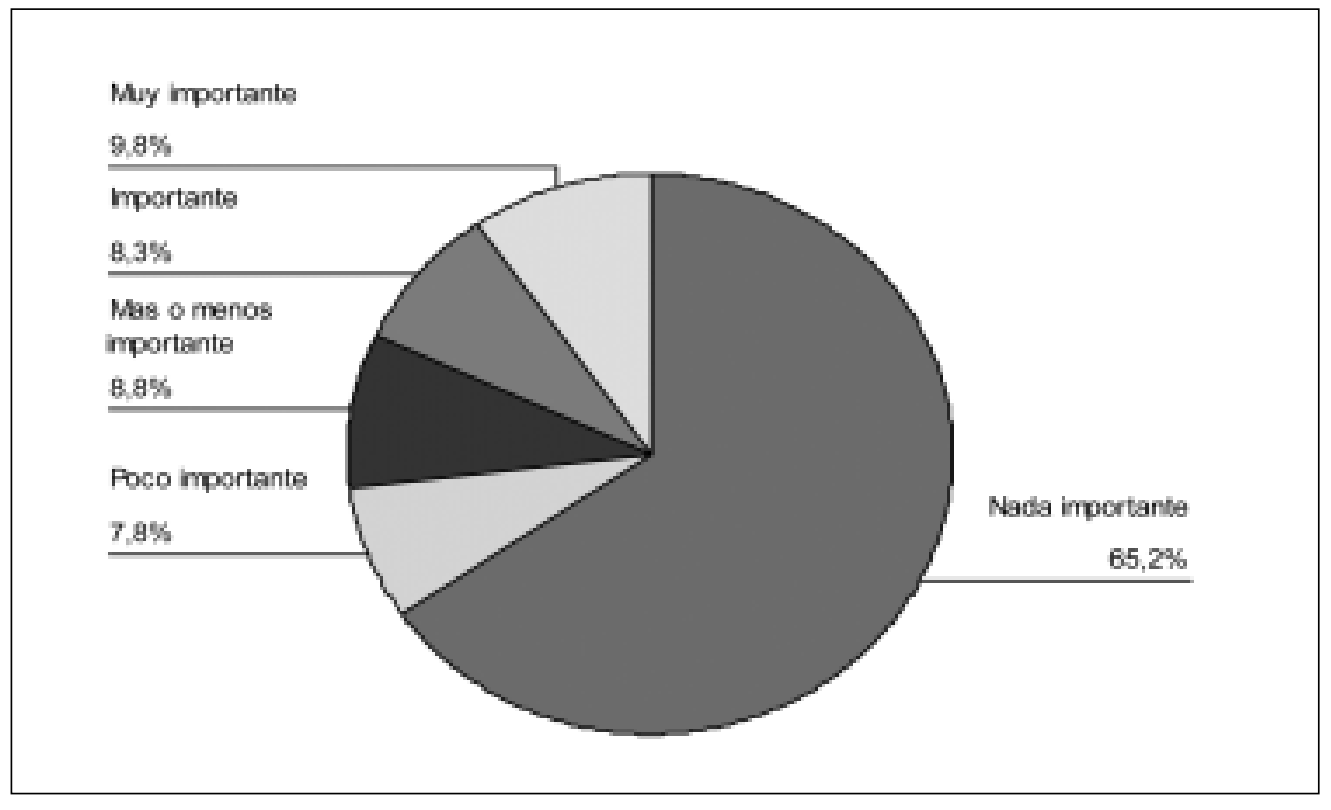

Los niños difieren notoriamente en sus apreciaciones acerca de las siguientes cualidades (véanse gráficos 9 , 10 y 11$)$.

Gráfico 9. Ser fuerte, no dejarse de nadie

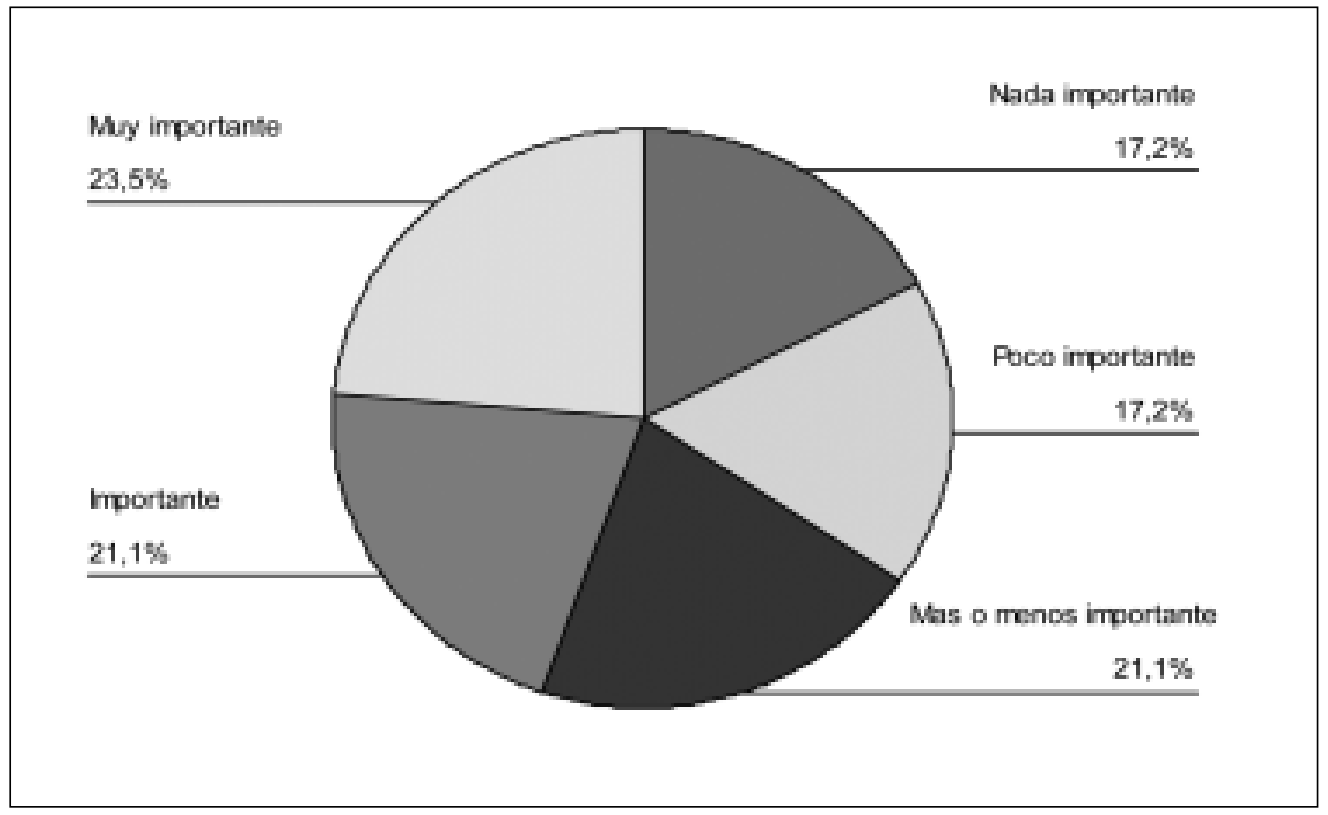


Gráfico 10. Ser chistoso, hacer reír mucho a los compañeros

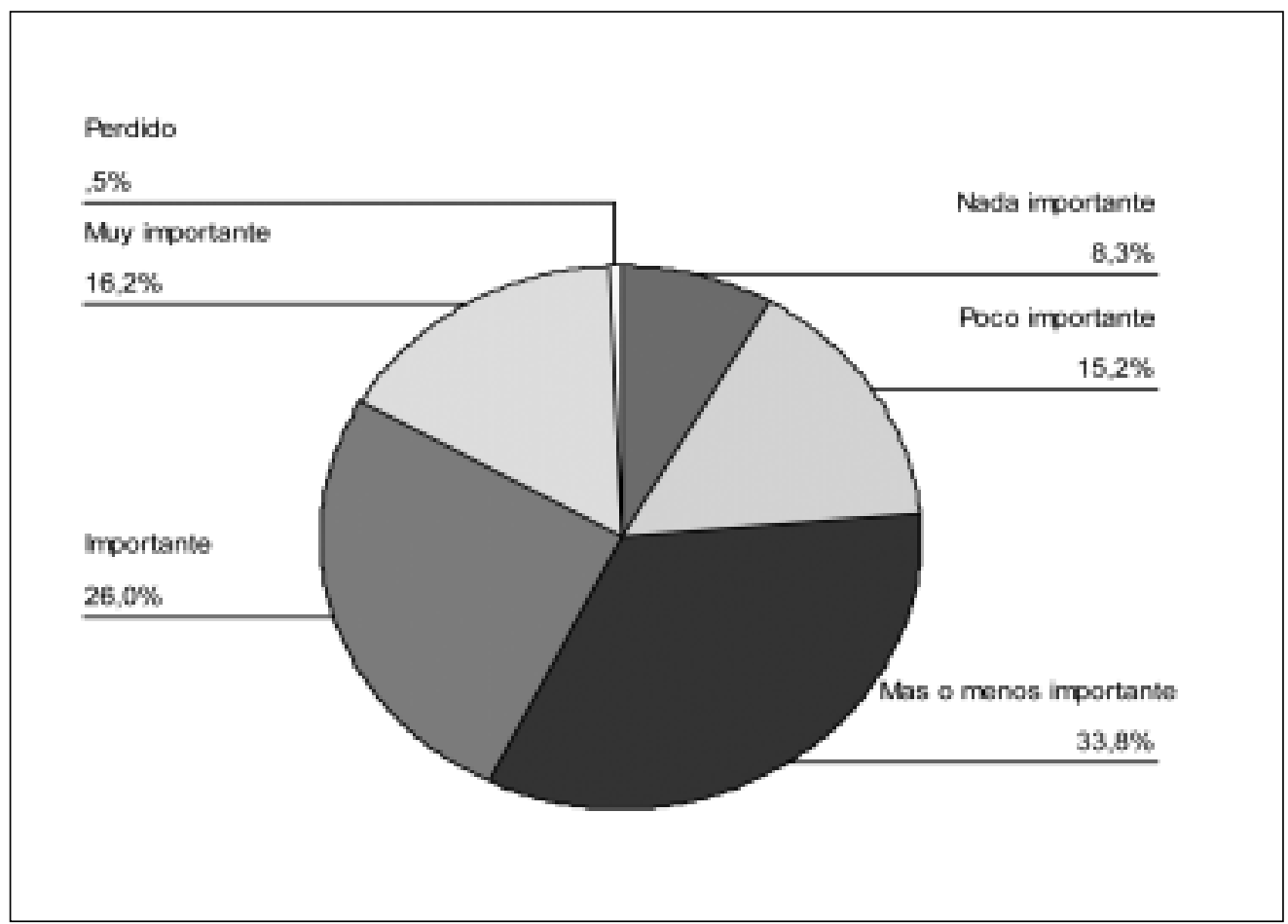

Gráfico 11. Tener buena pinta, ser bonito(a)

Muy importante

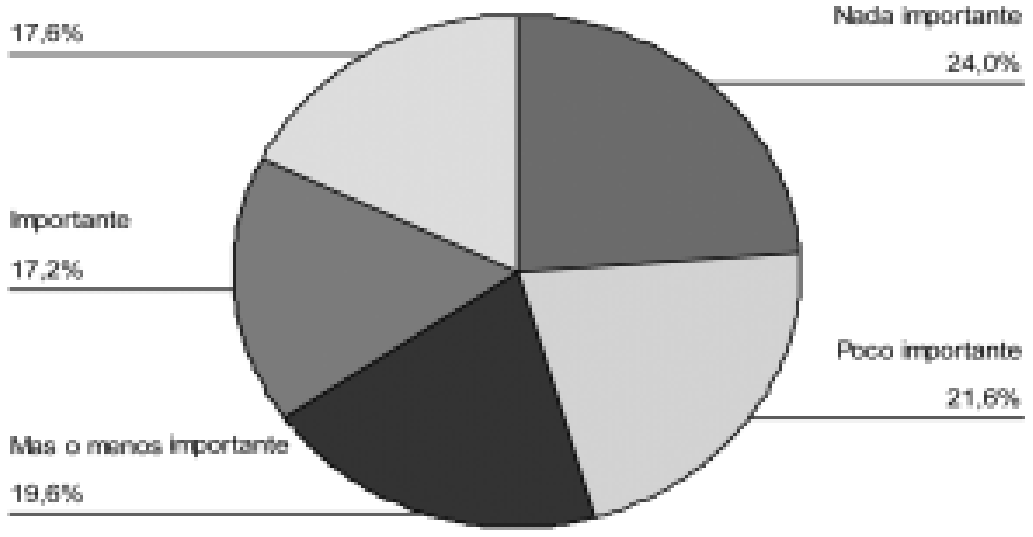


En la tabla 2, se muestran por orden de importancia las cualidades evaluadas y calificadas por la muestra de niños, con sus respectivas medias. Para definir el grado de importancia de cada cualidad se tomó como referencia la siguiente escala:

\begin{tabular}{cc}
\hline Promedio & Categoría \\
\hline $4.5-5.0$ & Muy importante \\
$3.5-4.5$ & Importante \\
$2.5-3.5$ & Más o menos importante \\
$1.5-2.5$ & Poco importante \\
$1-1.5$ & Nada importante \\
\hline
\end{tabular}

Tabla 2. Grado de importancia atribuido por los niños de ambos sexos a las distintas cualidades

\begin{tabular}{lcc}
\hline Cualidad & $\begin{array}{c}\text { Puntaje } \\
\text { Media }\end{array}$ & Categoría \\
\hline Ser generoso, saber compartir sus cosas & 4.88 & Muy importante \\
Ser respetuoso & 4.66 & Muy importante \\
Ser solidario, ayudar a los demás & 4.58 & Muy importante \\
Ser seguro de sí mismo & 4.52 & Muy importante \\
Ser fiel con los amigos & 4.50 & Muy importante \\
Ser sociable, relacionarse con otros & 4.40 & Importante \\
Ser sincero, infundir mucha confianza & 4.37 & Importante \\
Ser optimista, no desanimarse fácil & 4.27 & Importante \\
Ser simpático y alegre & 4.07 & Importante \\
Ser aplicado, sacar buenas notas & 3.86 & Importante \\
Ser discreto, prudente, evitar meterse & 3.81 & Importante \\
en lo que no le importa & & Importante \\
Ser inteligente & 3.79 & Más o menos importante \\
Ser buen deportista & 3.30 & Más o menos importante \\
Ser chistoso, hacer reír mucho & 3.27 & Más o menos importante \\
a los compañeros & 3.26 & Más o menos importante \\
Ser buen conversador & 3.22 & Más o menos importante \\
Ser valiente, arriesgado & 3.17 & \\
Ser fuerte, no dejarse de nadie & 2.83 & \\
Tener buena pinta, ser bonito(a) & & Pánte \\
Ser bravo, hacerse respetar & & \\
Ser travieso, molestar mucho en clase & & \\
\hline
\end{tabular}


- ¿Qué tanto coinciden los niños en sus juicios sobre el grado de importancia que tienen distintos defectos para llegar a ser rechazados dentro de un grupo?

La mayoría de los niños coincide en considerar muy importantes los siguientes defectos (ver gráficos 12 , 13 y 14$)$ :

- $\quad$ Ser irrespetuoso, agresivo con los otros (68.1\%).

- $\quad$ Ser mentiroso, no inspirar confianza (62.7\%).

- $\quad$ Ser intenso, andar metiéndose en todo (53.4\%).

Gráfico 12. Ser irrespetuoso, agresivo con los otros

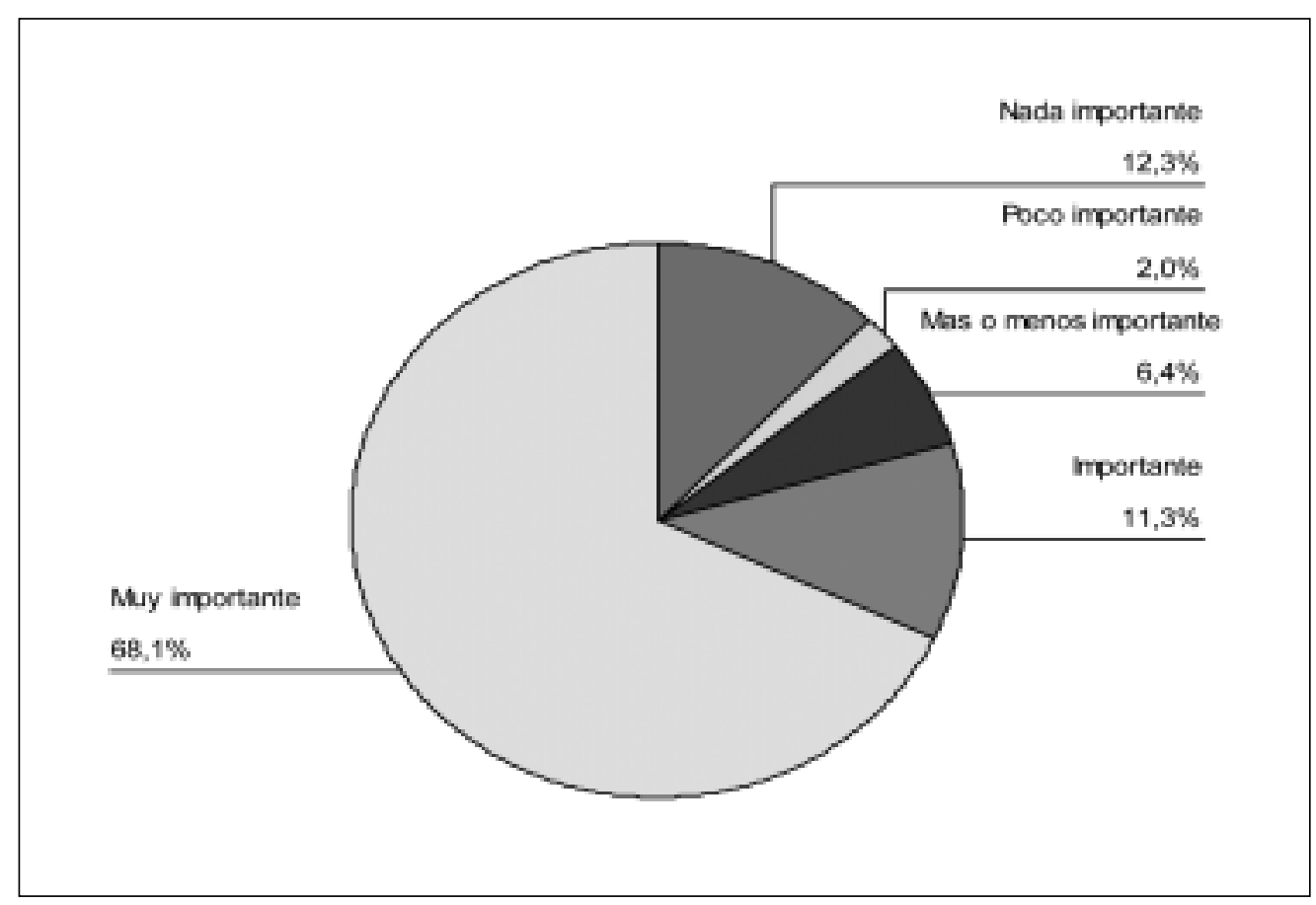


Gráfico 13. Ser mentiroso. no inspirar confianza

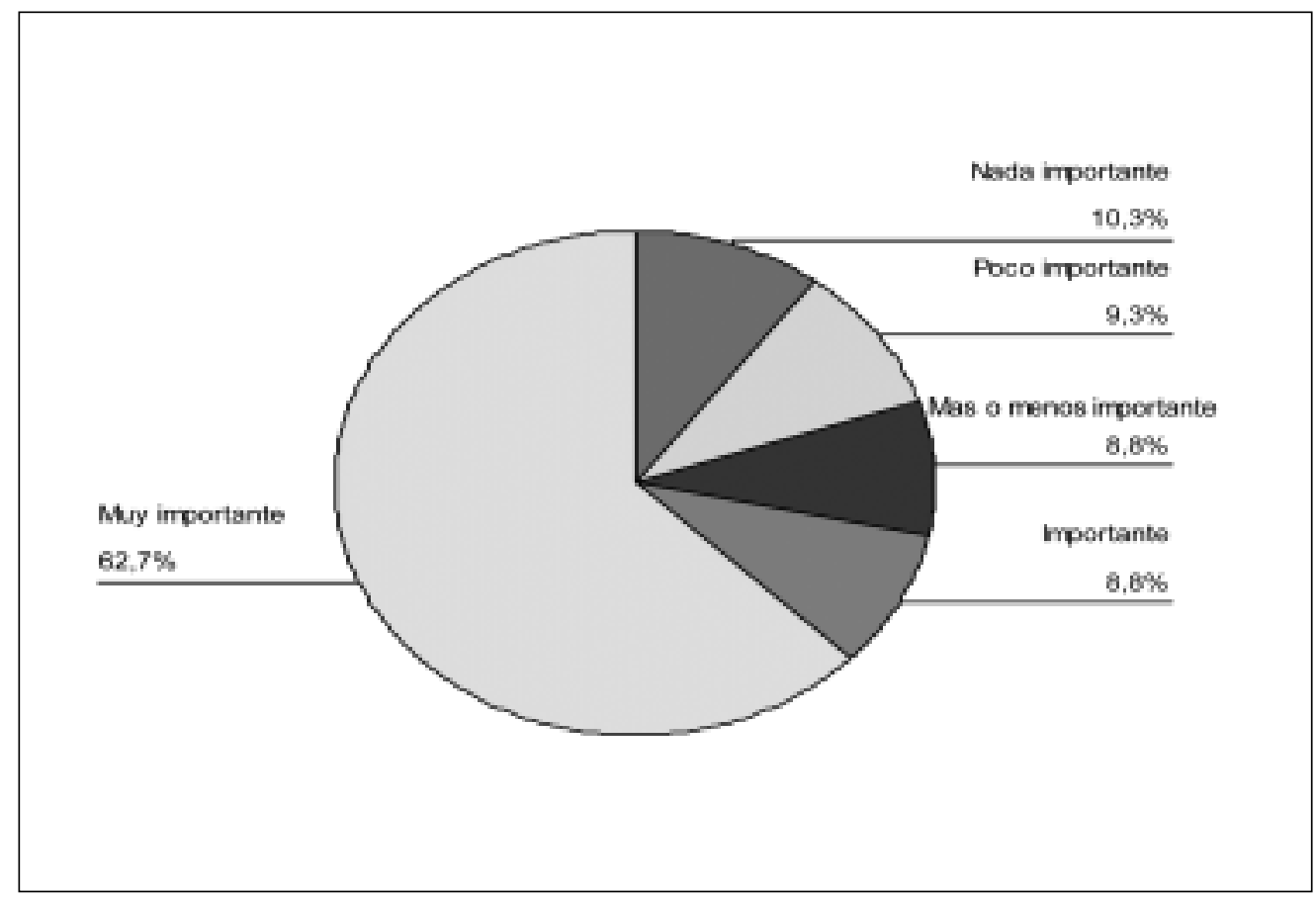

Gráfico 14. Ser muy intenso, andar metiéndose en todo

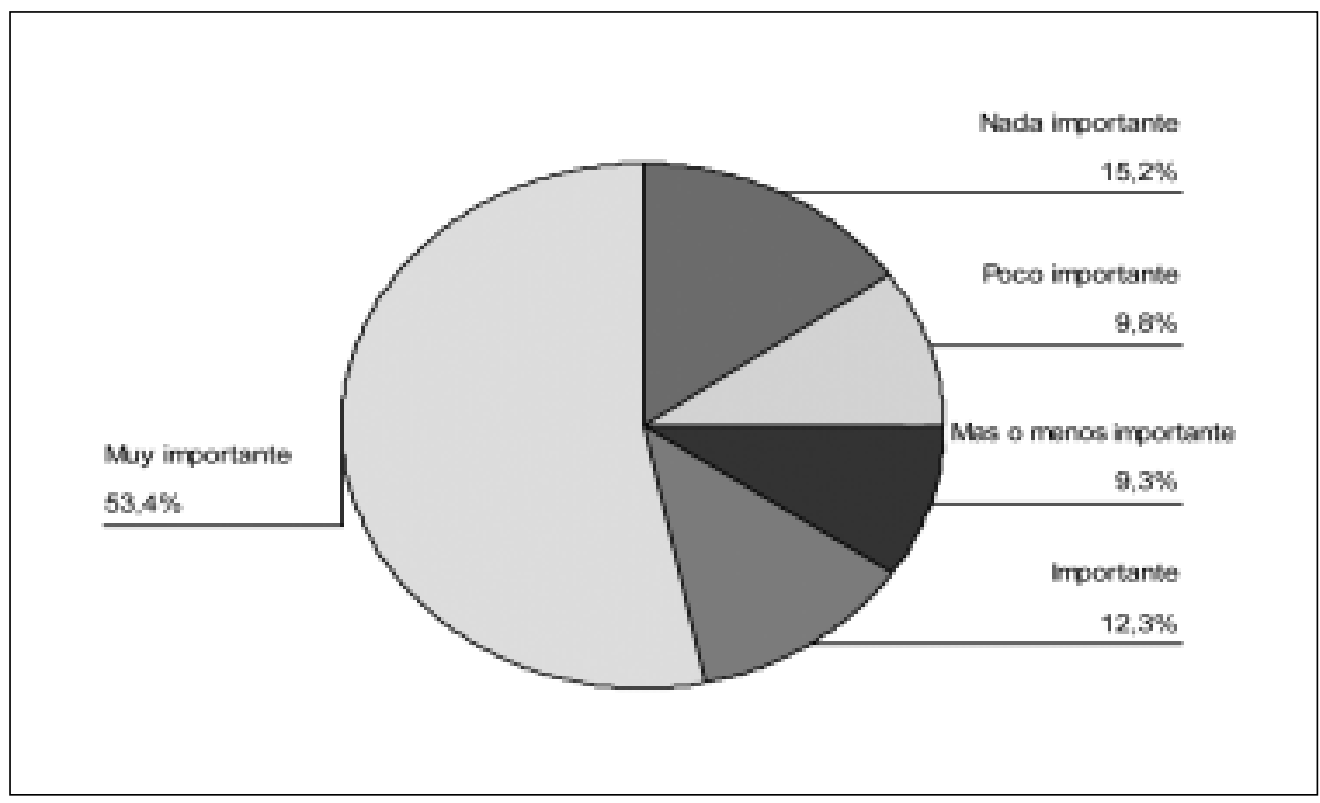


Según los niños, el defecto que tiene menor importancia para ser rechazado es el ser mal deportista. En efecto, el $42.5 \%$ coincidó en considerarlo nada importante (gráfico 15).

Gráfico 15. Ser mal deportista

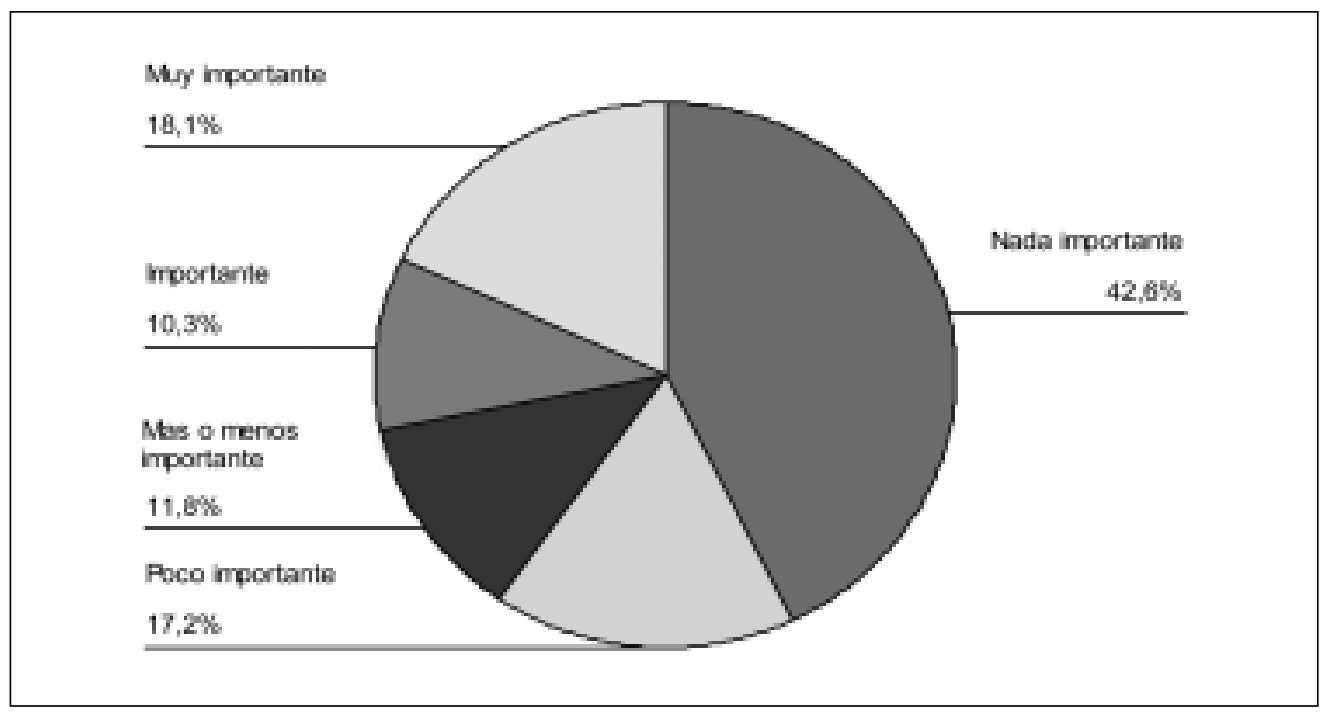

Los niños difieren notoriamente en sus apreciaciones acerca de los siguientes defectos (gráficos 16, 17 y 18):

- Ser callado, conversar poco con los otros

- $\quad$ Ser cobarde, que todo le dé miedo

- $\quad$ Ser feo(a), vestirse mal

Gráfico 16. Ser callado, conversar poco con los otros

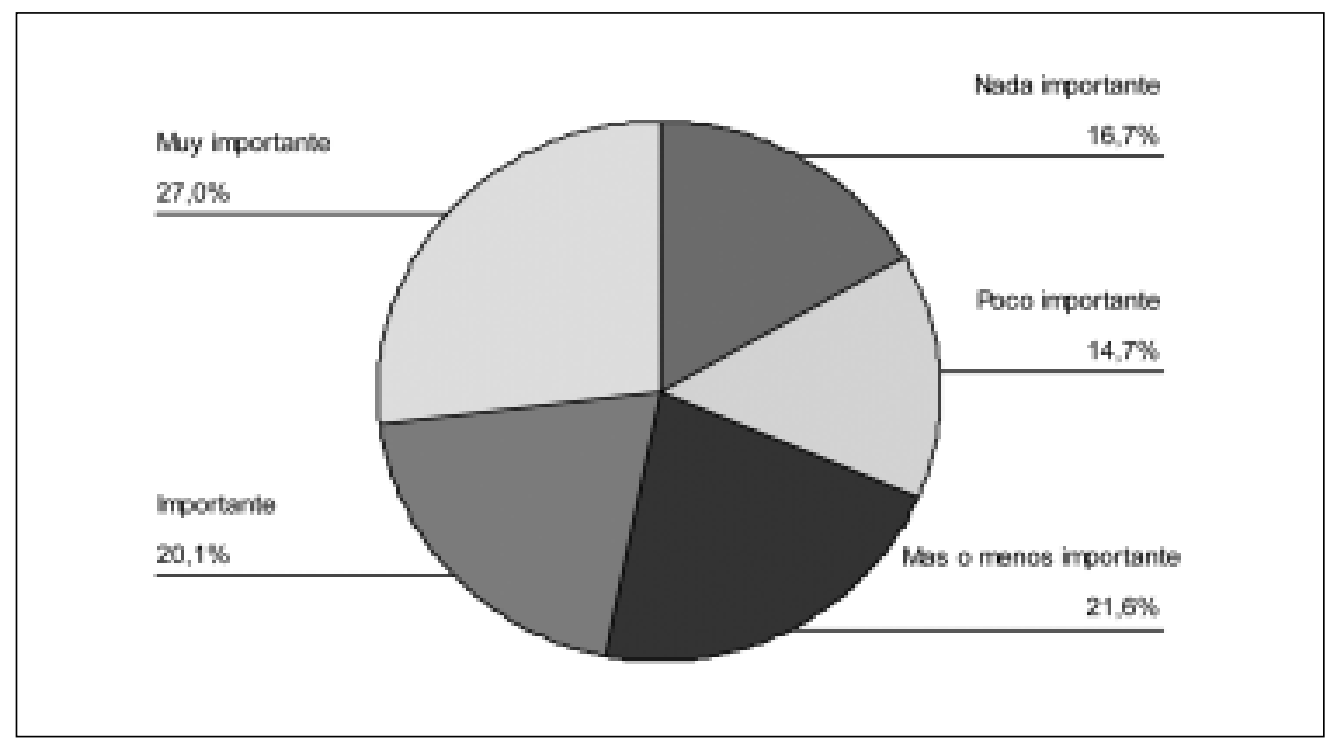


Gráfico 17. Ser cobarde, que todo le dé miedo

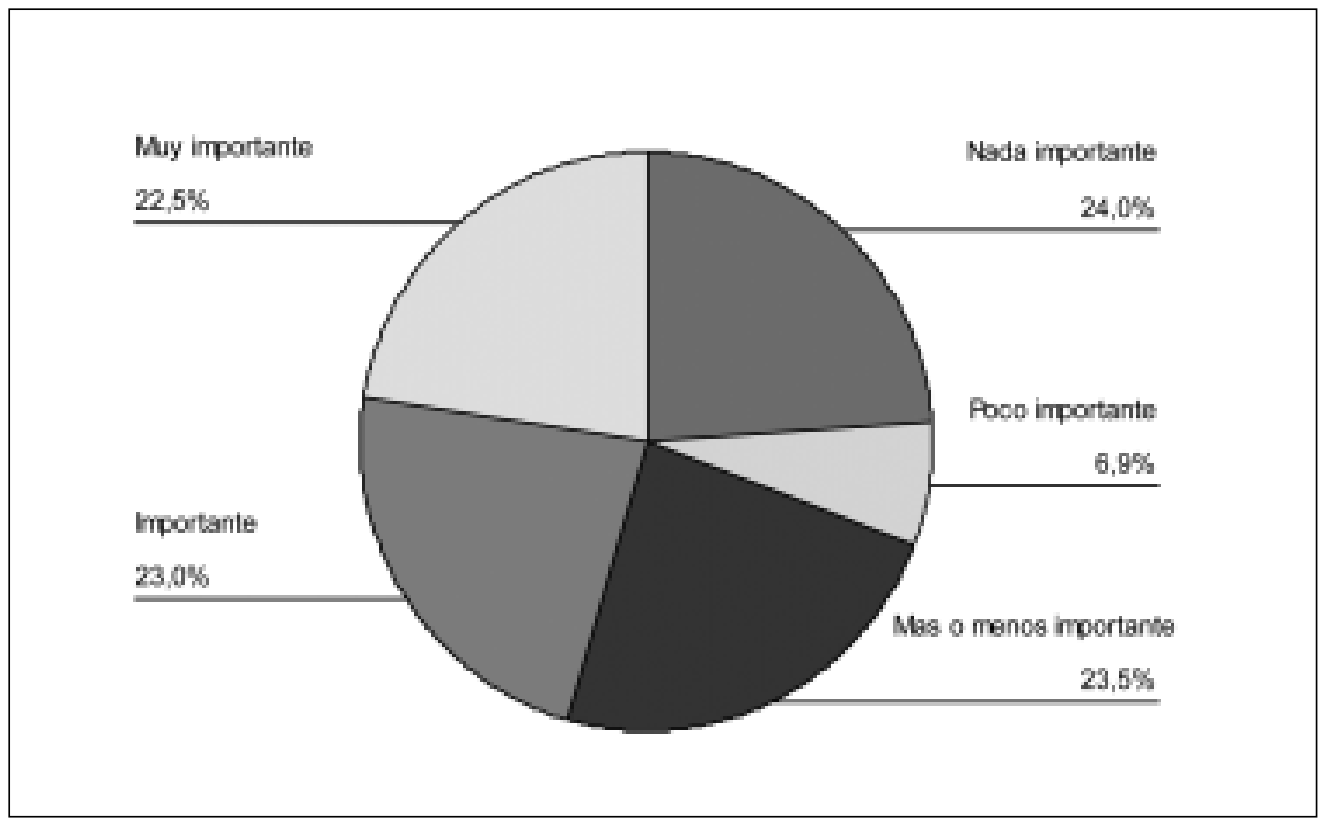

Gráfico 18. Ser feo(a), vestirse mal

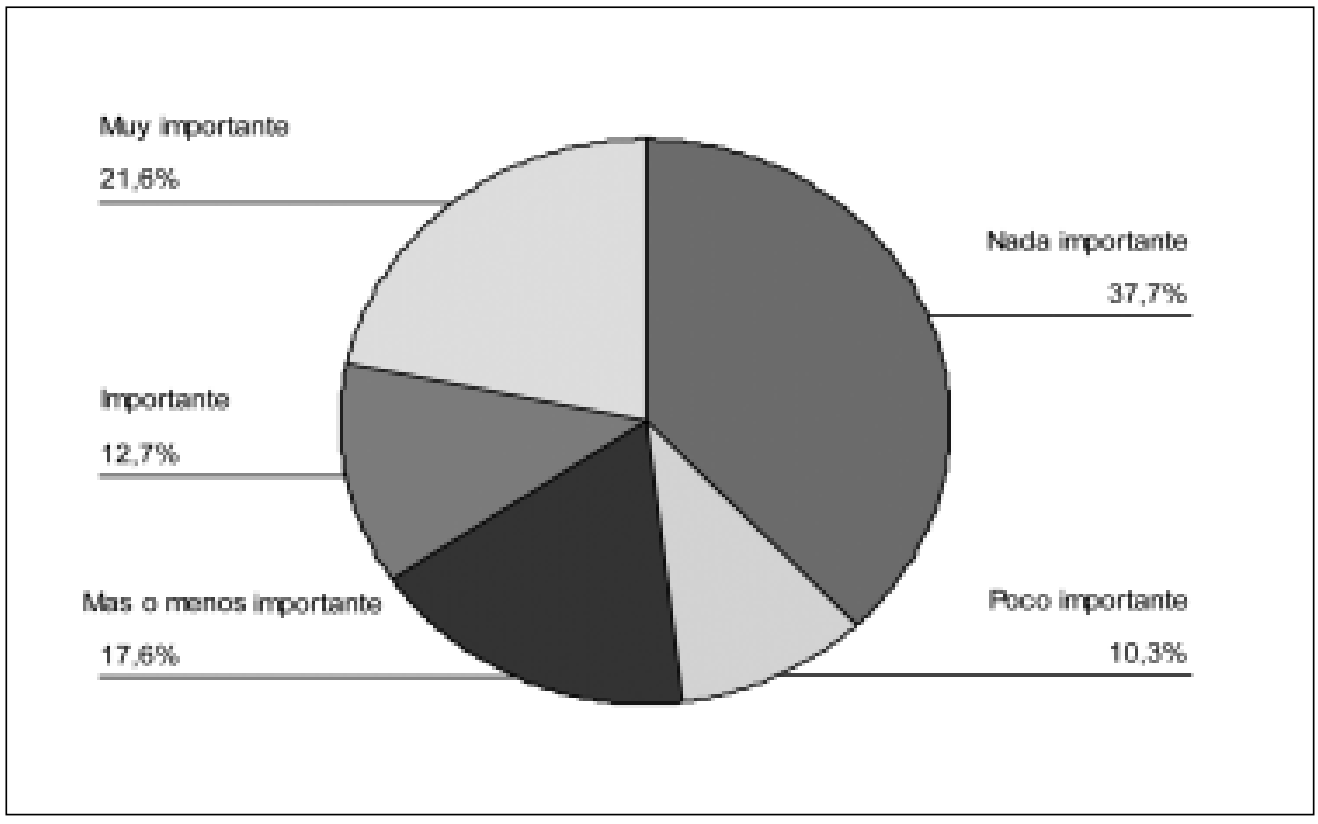


En la tabla 3, se muestran por orden de importancia los defectos evaluados y calificados por los(as) niños(as), con sus respectivas medias. Para estimar su grado de importancia, se siguió el mismo procedimiento ya descrito en relación con las cualidades.

Tabla 3. Grado promedio de importancia atribuido por los niños de ambos sexos a los distintos "defectos"

\begin{tabular}{|c|c|c|}
\hline Defectos & $\begin{array}{c}\text { Puntaje } \\
\text { Media }\end{array}$ & Categoría* \\
\hline Ser irrespetuoso, agresivo con los otros & 4.21 & Importante \\
\hline Ser mentiroso, no inspirar confianza & 4.04 & Importante \\
\hline Ser egoísta & 4.01 & Importante \\
\hline Ser desleal con los amigos, "sapo" & 3.91 & Importante \\
\hline Ser poco colaborador, no ayudar a los demás & 3.86 & Importante \\
\hline Ser antipático, gruñón & 3.83 & Importante \\
\hline Ser muy intenso, andar metiéndose en todo & 3.79 & Importante \\
\hline Ser retraído, relacionarse muy poco con los otros niños & 3.72 & Importante \\
\hline Ser pesimista, desanimarse muy pronto & 3.49 & Más o menos importante \\
\hline Ser aburrido, aguafiestas & 3.48 & Más o menos importante \\
\hline Ser inseguro de sí mismo & 3.48 & Más o menos importante \\
\hline Ser retraído, dejar que los otros manden o se aprovechen de él & 3.46 & Más o menos importante \\
\hline Ser desaplicado, que le vaya mal en el colegio & 3.37 & Más o menos importante \\
\hline Ser demasiado juicioso en clase, “lambón” con los profesores & 3.33 & Más o menos importante \\
\hline Ser débil, dejarse pegar de otros & 3.32 & Más o menos importante \\
\hline Ser callado, conversar poco con los otros & 3.26 & Más o menos importante \\
\hline Ser tonto, hacer o decir muchas bobadas & 3.24 & Más o menos importante \\
\hline Ser cobarde, que todo le dé miedo & 3.13 & Más o menos importante \\
\hline Ser feo, vestirse mal & 2.70 & Más o menos importante \\
\hline Ser mal deportista & 2.44 & Poco importante \\
\hline Otra & 1.54 & Poco importante \\
\hline
\end{tabular}

\section{- ¿Se diferencian las niñas de los niños en cuanto al grado de importancia que le atribuyen a las distintas cualidades?}

En la tabla 4 puede observarse que existen algunas diferencias estadísticamente significativas en cuanto al grado de importancia que niños y niñas le atribuyen a las distintas cualidades. Las niñas le dieron mayor importancia a todas aquellas cualidades en las que se encontraron diferencias significativas. 
Tabla 4. Cualidades en las que los niños y niñas difieren significativamente en sus apreciaciones

\begin{tabular}{lc}
\hline Cualidad & $\begin{array}{c}\text { Nivel de significancia } \\
\text { (Prueba T) }\end{array}$ \\
\hline Ser chistoso, hacer reír mucho a los compañeros & 0.00 \\
Ser respetuoso & 0.01 \\
Ser bravo, hacerse respetar & 0.02 \\
Tener buena pinta & 0.03 \\
Ser valiente & 0.06 \\
\hline
\end{tabular}

- ¿Difieren los niños y las niñas en sus apreciaciones sobre la importancia de los distintos defectos?

En cuanto al grado de importancia atribuido a los distintos defectos, sólo se encontraron diferencias significativas entre niños y niñas en relación con un defecto: "Ser débil, dejarse pegar de los otros". Nuevamente fueron las niñas quienes le atribuyeron mayor importancia a esta característica de comportamiento (tabla 5).

Tabla 5. Defectos, respecto a los cuales niños y niñas difieren significativamente en sus apreciaciones

\begin{tabular}{lc}
\hline Defectos & $\begin{array}{c}\text { Nivel de significancia } \\
\text { Prueba T }\end{array}$ \\
\hline Ser débil dejarse pegar de otros & 0.00 \\
\hline
\end{tabular}

\section{- ¿Influye el grado de integración social de los niños en el grupo sobre los juicios que expresa acerca de la importancia de las distintas cualidades y defectos?}

Para buscar respuesta a esta pregunta, se calculó el puntaje de integración social obtenido por cada niño en el test sociométrico. Este puntaje resulta de contar el número de veces que cada persona es mencionada en las categorías de vinculación, aceptación y cooperación social, a lo que se le resta luego el número de veces que se le menciona en las categorías de rechazo y aislamiento social. Siguiendo este procedimiento, hubo 58 niños que obtuvieron puntajes negativos y fueron asignados al grupo denominado "niños excluidos". Los juicios de estos niños fueron comparados con los de los 58 niños que obtuvieron los puntajes positivos más altos en el test sociométrico y que conformaron, por lo tanto, el grupo denominado "niños muy incluidos".

En las tablas 6 y 7 se observa que no hubo diferencias significativas en los juicios que los niños "excluidos" y niños "muy incluidos" expresaron acerca de la importancia de distintas cualidades y defectos en las relaciones sociales con sus pares. La intersección de las variables sexo e integración social tampoco arrojó diferencias significativas; es decir que el resultado anterior se confirma, independientemente del género de los niños interrogados. Para cada cualidad, se indica el puntaje T y su nivel de significancia. 
Tabla 6. Diferencias en la estimación del grado de importancia de las distintas cualidades agrupando los niños según grado de integración y según sexo y grado de integración.

\begin{tabular}{|c|c|c|}
\hline Cualidad & Integración & $\begin{array}{c}\text { Sexo e } \\
\text { integración }\end{array}$ \\
\hline Ser respetuoso & $0.43(0.652)$ & $1.28(2,79)$ \\
\hline Ser chistoso, hace reír mucho a los compañeros & $2,535(0.82)$ & $0,193(0.825)$ \\
\hline Ser inteligente & $0.594(0.55)$ & $0.348(0.706)$ \\
\hline Ser fuerte, no dejarse de nadie & $2.207(0.113)$ & $2.416(0.92)$ \\
\hline Ser simpático y alegre & $3.795(0.32)$ & $1.368(0.25)$ \\
\hline Ser sociable, relacionarse con otros & $2.827(0.62)$ & $3.366(0.37)$ \\
\hline Tener buena pinta, ser bonito(a) & $1.318(2.70)$ & $1.947(0.145)$ \\
\hline Ser bravo, hacerse respetar & $0.723(0.486)$ & $2.44(0.789)$ \\
\hline Ser generoso, saber compartir sus cosas & $1.090(0.34)$ & $0.549(0.58)$ \\
\hline Ser valiente, arriesgado & $0.377(0.687)$ & $0.378(0.69)$ \\
\hline Ser aplicado, sacar buenas notas & $1.244(2.91)$ & $3.58(6.99)$ \\
\hline Ser travieso, molestar mucho en clase & $1.06(0.89)$ & $8.97(0.41)$ \\
\hline Ser buen deportista & $3.620(0.28)$ & $0.32(0.73)$ \\
\hline Ser sincero, infundir mucha confianza & $4.077(0.18)$ & $0.59(0.56)$ \\
\hline Ser fiel con los amigos & $3.266(0.40)$ & $1.098(3.35)$ \\
\hline Ser optimista, no desanimarse fácil & $0.640(0.53)$ & $0.43(0.65)$ \\
\hline Ser seguro de sí mismo & $0.82(0.44)$ & $0.25(0.79)$ \\
\hline Ser solidario, ayudar a los demás & $0.96(0.39)$ & $2.014(0.14)$ \\
\hline Ser buen conversador & $1.297(0.276)$ & $1.231(0.294)$ \\
\hline $\begin{array}{l}\text { Ser discreto, prudente, evitar meterse } \\
\text { en lo que no le importa }\end{array}$ & $3.86(0.689)$ & $1.843(0.16)$ \\
\hline
\end{tabular}


Tabla 7. Diferencias en la estimación del grado de importancia de los distintos defectos agrupando los niños según grado de integración y según sexo y grado de integración

\begin{tabular}{lcc}
\hline Defecto & Integración & $\begin{array}{c}\text { Sexo* } \\
\text { Integración }\end{array}$ \\
\hline Ser irrespetuoso & $2.897(0.58)$ & $2.264(1.07)$ \\
Ser aguafiestas & $0.674(0.51)$ & $0.169(0.845)$ \\
Ser tonto, hacer o decir muchas bobadas & $0.26(0.77)$ & $1.424(0.24)$ \\
Ser débil, dejarse pegar de otros & $0.186(0.83)$ & $1.183(0.30)$ \\
Ser antipático, gruñón & $0.53(0.94)$ & $0.853(0.42)$ \\
Ser retraído, relacionarse muy poco con los otros niños & $1.020(0.36)$ & $0.631(0.53)$ \\
Ser feo, vestirse mal & $0.217(0.80)$ & $0.90(0.91)$ \\
Dejar que los otros lo manden o se aprovechen de él & $0.95(0.39)$ & $0.21(0.80)$ \\
Ser egoísta & $0.52(0.60)$ & $0.66(0.51)$ \\
Ser cobarde, que todo le dé miedo & $1.905(0.15)$ & $0.73(0.92)$ \\
Ser desaplicado, que le vaya mal en el colegio & $0.26(0.77)$ & $0.27(0.75)$ \\
Ser demasiado juicioso en clase, "lambón con los profesores" & $0.69(0.50)$ & $0.20(0.81)$ \\
Ser mal deportista & $5.312(0.06)$ & $0.366(0.69)$ \\
Ser mentiroso, no inspirar confianza & $0.73(0.48)$ & $0.28(0.75)$ \\
Ser desleal con los amigos, "sapo" & $1.195(0.30)$ & $0.15(0.86)$ \\
Ser pesimista, desanimarse muy pronto & $0.28(0.75)$ & $0.14(0.868)$ \\
Ser inseguro de sí mismo & $0.80(0.45)$ & $1.291(0.27)$ \\
Ser poco colaborador, no ayudar a los demás & $1.727(0.18)$ & $0.35(0.70)$ \\
Ser callado, no conversar casi con otros & $0.129(0.88)$ & $1.415(0.245)$ \\
Ser muy intenso, andar metiéndose en todo & $0.54(0.58)$ & $0.17(0.84)$ \\
\hline
\end{tabular}

*Niñas “muy incluidas” se compararon con niñas “excluidas”. De la misma forma, se procedió con los niños varones.

\section{- ¿Tienden los niños a percibir las cualidades como si formaran distintos grupos?}

Al aplicar el análisis factorial a los datos arrojados por este estudio, se obtuvieron distintos grupos de cualidades. Estos grupos están definidos por la alta correlación que existe entre los juicios que expresaron los niños acerca de las cualidades que componen el grupo. En la tabla 8 puede observarse, por ejemplo, que los niños tienden a conceder una importancia semejante a cualidades como ser inteligente, ser aplicado, tener buena pinta y ser buen deportista. Otros grupos están conformados por las siguientes cualidades:

- $\quad$ Ser bravo, ser valiente, ser travieso, ser fuerte, ser chistoso y ser prudente.

- $\quad$ Ser fiel con los amigos, ser sincero, ser generoso. 
- $\quad$ Ser solidario, ser respetuoso, ser seguro de sí mismo.

- $\quad$ Ser optimista, ser conversador, ser simpático y alegre.

La cifra que aparece al frente de cada cualidad indica el grado en que se correlaciona con el conjunto de cualidades que componen el grupo.

Tabla 8. Correlaciones entre los juicios expresados por los niños de ambos sexos acerca de la importancia de las distintas cualidades. Resultados del análisis factorial

\begin{tabular}{|c|c|c|c|c|c|}
\hline \multicolumn{6}{|c|}{ Matriz de componentes rotados(a) } \\
\hline & \multicolumn{3}{|c|}{ Componente } & \multirow[b]{2}{*}{4} & \multirow[b]{2}{*}{5} \\
\hline & 1 & 2 & 3 & & \\
\hline Ser bravo, hacerse respetar & .672 & & & & \\
\hline Ser travieso, molestar mucho en clase & .644 & & & & \\
\hline Ser valiente, arriesgado & .607 & & & & \\
\hline Ser fuerte, no dejarse de nadie & .585 & & & & \\
\hline Ser chistoso, hacer reír mucho a los compañeros & .571 & & & & \\
\hline $\begin{array}{l}\text { Ser discreto, prudente, evitar meterse en lo que } \\
\text { no le importa }\end{array}$ & .483 & & & & \\
\hline Ser inteligente & & .769 & & & \\
\hline Ser aplicado, sacar buenas notas & & .766 & & & \\
\hline Tener buena pinta, ser bonito(a) & & .590 & & & \\
\hline Ser buen deportista & .430 & .580 & & & \\
\hline Ser fiel con los amigos & & & .755 & & \\
\hline Ser sincero, infundir mucha confianza & & & .630 & & \\
\hline Ser generoso, saber compartir sus cosas & & & .585 & & \\
\hline Ser solidario, ayudar a los demás & & & & .679 & \\
\hline Ser respetuoso & & & & .648 & \\
\hline Ser seguro de sí mismo & & & & .642 & \\
\hline Ser optimista, no desanimarse fácil & & & & & .723 \\
\hline Ser buen conversador & & & & & .613 \\
\hline Ser simpático y alegre & & & & & .524 \\
\hline Ser sociable, relacionarse con todos & & & & & \\
\hline
\end{tabular}

* Método de extracción: análisis de componentes principales. Método de rotación: Normalización Equamax con Kaiser. La rotación ha convergido en 8 iteraciones.

Al realizar el mismo análisis en relación con los defectos, encontramos los grupos que aparecen especificados en la tabla 8. En este caso obsérvese que hay varios defectos que podrían asignarse simultánea- 
mente a dos grupos diferentes. Si damos prelación a la correlación más alta, obtendríamos los siguientes grupos de defectos:

- Ser antipático, ser irrespetuoso o agresivo, ser tonto, ser aburrido y ser muy intenso.

- Ser desleal con los amigos, ser mentiroso, ser egoísta, ser demasiado juicioso en clase y ser muy pesimista.

- $\quad$ Ser cobarde, ser débil, dejar que otros lo manden y ser retraído.

- $\quad$ Ser callado, ser poco colaborador, ser inseguro de sí mismo.

- $\quad$ Ser desaplicado, ser feo, ser mal deportista.

Tabla 9. Correlaciones entre los juicios expresados por los niños de ambos sexos acerca de la importancia de los distintos defectos. Resultados del análisis factorial

\begin{tabular}{|c|c|c|c|c|c|}
\hline \multicolumn{6}{|c|}{ Matriz de componentes rotados(a) } \\
\hline & \multicolumn{5}{|c|}{ Componente } \\
\hline & 1 & 2 & 3 & 4 & 5 \\
\hline Ser antipático, gruñón & .717 & .415 & & & \\
\hline Ser irrespetuoso, agresivo con los otros & .686 & .413 & & & \\
\hline Ser tonto, hacer o decir muchas bobadas & .686 & & & & \\
\hline Ser aburrido, aguafiestas & .633 & & & & \\
\hline Ser muy intenso, andar metiéndose en todo & .466 & & & .460 & \\
\hline Ser desleal con los amigos, "sapo" & & .752 & & & \\
\hline Ser mentiroso, no inspirar confianza & & .669 & & & \\
\hline Ser egoísta, no saber compartir sus cosas & .463 & .647 & & & \\
\hline $\begin{array}{l}\text { Ser demasiado juicioso en clase, "lambón" } \\
\text { con los profesores }\end{array}$ & & .511 & & & \\
\hline Ser pesimista, desanimarse muy pronto & & .480 & & .413 & \\
\hline Ser cobarde, que todo le dé miedo & & & .745 & & \\
\hline Ser débil, dejarse pegar de otros & & & .711 & & \\
\hline Dejar que los otros lo manden o se aprovechen de él & & & .681 & & \\
\hline Ser retraído, relacionarse muy poco con los otros niños & .424 & & .432 & & \\
\hline Ser callado, no conversar casi con otros & & & & .862 & \\
\hline Ser poco colaborador, no ayudar a los demás & & & & .479 & \\
\hline Ser inseguro de sí mismo & & & & .416 & \\
\hline Ser mal deportista & & & & & .724 \\
\hline Ser desaplicado, que le vaya mal en el colegio & & & & & .664 \\
\hline Ser feo, vestirse mal & & & & & .617 \\
\hline
\end{tabular}

Método de extracción: Análisis de componentes principales. Método de rotación: Normalización Equamax con Kaiser. La rotación ha convergido en 13 iteraciones. 


\section{Discusión}

A partir de los resultados obtenidos, se puede afirmar que la hipotesis 1 se confirmó parcialmente. Es decir, los niños coincidieron en sus apreciaciones sobre la importancia de algunas cualidades, como ser respetuoso, fiel, generoso, seguro, solidario o sociable, pero difirieron notablemente en sus apreciaciones sobre otras cualidades, como ser fuerte, chistoso o tener buena pinta. Al observar más detenidamente las cualidades respecto a las cuales los niños mostraron mayor coincidencia en sus juicios, salta a la vista que, exceptuando un solo caso (véase gráfico 8 ), son además aquellas a las que atribuyeron mayor valor.

Aquí parecen reflejarse dos influencias importantes: una procedería de consensos altamente difundidos en la cultura sobre lo que significa ser un buen amigo o ser una persona exitosa socialmente.

En efecto, el respeto, la lealtad, la sinceridad y la generosidad se destacan frecuentemente como atributos propios de los "buenos" amigos, mientras que la seguridad en sí mismo, la sociabilidad y la solidaridad son actitudes por medio de las cuales las personas logran prestigio en los grupos sociales (Wentzel y Erdley, 1993). La otra influencia importante procedería del particular estadio del desarrollo cognoscitivo y moral en que se encuentran los niños. Desde la perspectiva de Kohlberg, en el estadio convencional, los niños entenderían ya el principio de reciprocidad que, definido coloquialmente, rezaría: "Haz por otros lo que te gustaría que hicieran por ti" o "no hagas a otros lo que no te gustaría que te hicieran a ti". Este principio es precisamente el fundamento de valores de convivencia como el respeto, la lealtad y la generosidad (Jaramillo, 2002).

Cabe destacar también el hecho de que haya habido poco consenso en la importancia que los niños atribuyeron a cualidades como ser fuerte, ser chistoso o tener belleza física. Estos atributos, que frecuentemente son fuente de popularidad o éxito social, no necesariamente fueron percibidos como un factor clave para ser querido o aceptado dentro de un grupo escolar. Cabría preguntarse si la popularidad y la aceptación social son percibidas por los niños como fenómenos correlativos o si hacen una clara distinción entre ellas.

Varios grupos focales que se han realizado en el contexto de esta investigación, y que serán objeto de análisis en una publicación posterior, sugieren que la última opción es probablemente más cercana a la realidad. A lo anterior apunta también el hecho de que la mayoría de los niños haya coincidido en no dar importancia al ser travieso o molestar mucho en clase como fuente de aceptación social: que alguien se haga notar dentro de un grupo escolar no significa necesariamente que sea aceptado o querido por sus compañeros.

Las estimaciones que hacen los niños sobre la importancia relativa de distintos defectos como fuentes de rechazo social tienden a confirmar varios hallazgos en la investigación precedente sobre el tema (véase Morison y Masten, 1991; Denham y Holt, 1993). En efecto, el defecto considerado más grave fue el irrespeto o la agresión. También la falta de asertividad y sinceridad en la comunicación y la intrusividad ("ser muy intenso") fueron destacadas como defectos graves en el contexto social escolar (véanse gráficos 13 y 14).

Ser callado, no tener una apariencia física bonita o ser mal deportista no parecen tener, en cambio, la importancia que por sentido común se les tiende a atribuir. Respecto a estos supuestos defectos, las apreciaciones de los niños son muy disímiles.

La hipótesis 2 se confirmó sólo parcialmente. Se observa que hay diferencias significativas entre niños y niñas en sus apreciaciones sobre algunas cualidades, como el ser respetuoso, ser chistoso, ser bravo o tener buena pinta. Resulta interesante que las niñas le den más importancia a estas cualidades que los niños. En lo relacionado con los defectos, sólo en un caso se observaron diferencias significativas entre las apreciaciones de niños y niñas, y nuevamente fueron las niñas quienes dieron mayor importancia al "ser débil, dejarse pegar de los otros". Todo lo anterior parece 
estar indicando que el espectro de comportamientos y actitudes que tienen en cuenta las niñas al valorar la calidad de sus relaciones sociales es notablemente más amplio que el de los niños. Por otro lado, es interesante constatar que los niños y las niñas están en principio de acuerdo con respecto a las actitudes (y valores) que serían claves para lograr una buena aceptación dentro del grupo de pares.

La hipótesis 3 no se confirmó, pues en ningún caso se observaron diferencias significativas entre los juicios que expresaron niños con altos niveles de inclusión social y niños predominantemente excluidos. Este resultado se mantuvo cuando se hizo el análisis por separado de niños y niñas, con lo que pierde peso la suposición de que los niños rechazados perciben las relaciones sociales de una manera cualitativamente distinta a los niños que gozan de aceptación social. Expresado en otras palabras, la posición social dentro de un grupo escolar parece estar más fuertemente relacionada con comportamientos y actitudes específicos que exhiben los niños en su interacción cotidiana con otros niños, que con la forma de procesar o interpretar información social.

A partir del análisis factorial realizado, se observó que los niños tendieron a asociar entre sí las distintas cualidades y defectos, con lo que pueden identificarse ciertos "perfiles" de compañeros que suelen estar presentes en los grupos escolares. Entre los perfiles más valorados encontramos los siguientes: a) Ser fiel, sincero, y generoso y b) Ser respetuoso, solidario, seguro de sí mismo y optimista (compárense tablas 2 y 8 ). Llama la atención que los niños perciban unificadamente rasgos como ser inteligente, aplicado, buen deportista y bonito (tener buena pinta), ya que describen características por las que se recibe frecuentemente reconocimiento en el medio escolar. Sin embargo, existe poco consenso entre ellos sobre la importancia que tienen para lograr aceptación dentro de un grupo escolar.

Entre los perfiles menos valorados se encuentran también dos que resulta interesante destacar (compárense tablas 3 y 9): a) Ser desleal con los amigos, mentiroso, egoísta, demasiado juicioso en clase y pesimista, y b) Ser antipático, irrespetuoso (agresivo), tonto, aburrido y muy intenso. Cabe preguntarse qué es lo que lleva a que estos rasgos aparezcan agrupados en las estimaciones que hacen los niños. ¿Cuál es el fundamento empírico para ello? En síntesis, puede afirmarse que la hipótesis 4 se confirma en gran medida, pero falta profundizar más en las implicaciones teóricas de estos resultados.

\section{Referencias}

Arenas, G. (1996). Investigación sobre la vida de las niñas en la escuela. Edición Estudios y Ensayos, Centro de Publicaciones de la Universidad de Málaga.

Bagwell, C., Newcomb, A. y Bukowski, W. (1998). Preadolescent friendship and peer rejection as predictors adult adjustment. Child Development, 69, 140-153.

Black, B. y Hazen, N. (1990). Social Status and patterns of communication in acquainted and unac-quainted preschool children. Developmental Psychology, 26, 379-387.

Bruner, J. y Haste, H. (1990). La elaboración del sentido: la construcción del mundo por el niño. Barcelona, Paidós. 9-29

Crick, N.R. y Dodge, K.A. (1994). A review and reformulation of social informationprocessing mechanisms in children's social adjustment. Psychological Bulletin, 115, 74101

Chitiva, M. (1997). Análisis del concepto de amistad a partir de la interacción entre niñas y niños de 9 a 11 años de edad. Bogotá. Tesis de Postgrado en Educación Sexual, Universidad Santo Tomás.

Coie, J.D., Dodge, K.A., Terry, R. \& Wright, B. (1991). The role of aggression in peer 
relations: an analysis of aggression episodes in boy's playgroups. Child Development, 62, 812-826.

Díaz Aguado, M. J. (1996). Escuela y tolerancia. Madrid, Pirámide. 72-78

Denham, S.A. y Holt, R.W. (1993). Preschooler's likeability as cause or consequence of their social behavior. Developmental Psychology, 29, 271-275.

Dozier, M. (1991). Functional measurement assessment of young children's ability to predict future behavior. Child Development, 62, 1091-1099.

Jaramillo, J. (2002). Familia y colegio: una Integración clave para el desarrollo educativo de los niños. Bogotá. Editorial Norma. pp. 168-169.

Jaramillo, J., Díaz, K., Niño, L., Tavera, A. y Velandia, A. Factores individuales, familiares y escolares asociados a la aceptación y el rechazo social en grupos de niños escolarizados entre los 9 y 11 años de edad. Diversitas, 205-215.

Kohlberg, L. (1999). La educación moral. Barcelona (España), Gedisa.

Ladd, G.W. (1999). Peer Relationships and Social Competence during early and middle Childhood. Annual Review of Psychology, 50, 336-

Ladd, G. y Burgess, K.B. (1999). Charting the relationships trajectories of aggressive, withdrawn and aggressive-withdrawn children during early grade school. Child Development, 70, 910-929.

Monjas Casares, I. (1996). Programa de enseñanza de habilidades de interacción social (PEHIS). Madrid, Cepe. p. 35-36.

Morison, P. y Masten, A.S. (1991). Peer reputation in middle school as a predictor of adaptation in adolescence: A seven year follow up. Child Development, 62, 991-1007.

Parker, J. G. y Seal, J. (1996). Forming, losing, renewing, and replacing friendships: applying temporal parameters to the assessment of children's friendship experiences. Child Development, 67, 2248-2268.

Piaget, J. (1965). The moral judgment of the child. New Cork, Free press. 327-341

Rice, Philip (1997). Desarrollo humano: un estudio del ciclo vital. Prentice Hall, México, 217

Rodríguez, M. y González, P. (2002). Evolución del concepto de amistad en niños de cuatro a doce años. Caracas, Anales, 2, 2.

Selman, R. (1980): The Growth of interpersonal understanding. New York: Academic Press.

Wentzel K.R. y Asher, S. R. (1995). The academic lives of neglected, rejected, popular and controversial children. Child Development, 66, $754-763$

Wentzel, K.R. y Erdley, C.A. (1993). Strategies for making friends: Relations to social behaviour and peer acceptance. Developmental Psychology, 29, 819-826 